\title{
Integrated genomic and transcriptomic analysis suggests KRT18 mutation and MTAP are key genetic alterations related to the prognosis between astrocytoma and glioblastoma
}

\author{
Zhiyong $\mathrm{Li}^{1}$, Yinghui Jin ${ }^{2}$, Qingping Zou ${ }^{3}$, Xiaofeng Shi ${ }^{4}$, Qianchao Wu ${ }^{3}$, Zhiying Lin ${ }^{1}$, Qun $\mathrm{He}^{3}$, \\ Guanglong Huang ${ }^{1}$, Songtao $\mathbf{Q i}^{1}$
}

${ }^{1}$ Department of Neurosurgery, Nanfang Hospital, Southern Medical University, Guangzhou, China; ${ }^{2}$ Department of Critical Care Medicine, Nanfang Hospital, Southern Medical University, Guangzhou, China; ${ }^{3}$ GenomiCare Biotechnology (Shanghai) Co., Ltd., Shanghai, China; ${ }^{4}$ Department of Neurosurgery, Longgang Central Hospital of Shenzhen, Shenzhen, China

Contributions: (I) Conception and design: S Qi, G Huang; (II) Administrative support: S Qi; (III) Provision of study materials or patients: Z Li, Y Jin, X Shi, Z Lin; (IV) Collection and assembly of data: Z Li, Q Zou, Q Wu, Q He; (V) Data analysis and interpretation: Z Li, Q Zou, G Huang, S Qi; (VI) Manuscript writing: All authors; (VII) Final approval of manuscript: All authors.

Correspondence to: Songtao Qi; Guanglong Huang. Department of Neurosurgery, Nanfang Hospital, Southern Medical University, No. 1838 Guangzhou Avenue North, Guangzhou, China. Email: qisongtaonfyy@126.com; hgl1020@qq.com.

Background: Astrocytoma and glioblastoma (GBM) are the two main subtypes of glioma, with the 2016 World Health Organization Classification of Tumors of the Central Nervous System (CNS WHO) classifying them into different grades. GBM is the most malignant among all CNS tumors with a 5-year survival rate of less than $5 \%$. Although the prognosis of patients with astrocytoma is better than that of GBM in general, patients with anaplastic astrocytoma (AA) and isocitrate dehydrogenase (IDH) wild type have a similar prognosis as GBM and entail a high risk of progression. Exploring the molecular driving force behind the malignant phenotype of astrocytoma and GBM will help explain the diversity of glioma and discover new drug targets.

Methods: We enrolled 12 patients with astrocytoma and 12 patients with GBM and performed wholeexome sequencing (WES) and RNA sequencing analysis on tumor samples from the patients.

Results: We found that the somatic mutation of KRT18, which is associated with cell apoptosis and adhesion by interacting with receptor 1-associated protein (TRADD) and pinin, was significantly enriched in astrocytoma, but rare in GBM. Copy number loss of MTAP, which is closely related to a poor prognosis of glioma, was found to be significantly enriched in GBM. In addition, different somatic copy number alteration (SCNA), gene expression, and immune cell infiltration patterns between astrocytoma and GBM were found.

Conclusions: This study revealed the distinct characteristics of astrocytoma and GBM at the DNA and RNA level. Somatic mutation of KRT18 and copy number loss of MTAP, two key genetic alterative genes in astrocytoma and GBM, have the potential to become therapeutic targets in glioma.

Keywords: Whole-exome sequencing (WES); KRT18 mutation; MTAP loss; immune cell infiltration

Submitted Mar 10, 2021. Accepted for publication Mar 29, 2021.

doi: $10.21037 / \mathrm{atm}-21-1317$

View this article at: http://dx.doi.org/10.21037/atm-21-1317

\section{Introduction}

Glioma is the most common tumor of the brain. Approximately $25.5 \%$ of all primary brain and other central nervous system (CNS) tumors and $80.8 \%$ of malignant brain tumors are glioma (1). The 2016 World Health Organization Classification of Tumors of the Central Nervous System (CNS WHO, 2016) classifies glioma into 
grade I to grade IV (2). Glioblastoma (GBM) is classified as grade IV and is the most malignant among all CNS tumors (1). The prognosis of GBM patients is poor, with a 5 -year survival rate of less than $5 \%(3,4)$. Tumor heterogeneity and the ambiguity of histomorphology are the two main challenges to the diagnosis and treatment of GBM.

Astrocytoma, another subtype of glioma, is characterized by isocitrate dehydrogenase (IDH1) or (IDH2) mutation, which can be accompanied by TP53 and ATRX mutation (5). According to the status of the $I D H$ gene, astrocytoma can be divided into 3 subtypes: $I D H$ mutant, $I D H$ wild type, and not otherwise specified (NOS). Among them, the $I D H$ mutation subtype has the potential to progress to GBM (6). Histologically, astrocytoma can be divided into diffuse astrocytoma (DA) and anaplastic astrocytoma (AA). DA, characterized by high differentiation and slow growth, is classified as low-grade glioma (grade II), while AA is classified as high-grade glioma (grade III) due its high proliferative activity $(7,8)$. Both molecular and histological characteristics are important to the prognosis of astrocytoma. AA patients with the $I D H$ mutation often have good prognosis, while AA patients with wild-type IDH1 have a poor prognosis and high risk of progression. There is no significant prognostic difference between AA with $I D H$ wild type and GBM with IDH wild type (9). Therefore, the same treatment protocol for GBM patients is recommended for patients with AA wild type $I D H$ if they also have a positive MGMT methylation status (10). Due to astrocytoma's poor prognosis and high risk of progression to GBM, it is important to explore the molecular characteristics of astrocytoma.

In this study, we collected tumor samples from 12 patients with astrocytoma and 12 patients with GBM, and performed whole-exome sequencing (WES) and RNA sequencing (RNA-seq) analysis on them to compare the genomic and transcriptomic characterization between these 2 tumors. We present the following article in accordance with the MDAR reporting checklist (available at http:// dx.doi.org/10.21037/atm-21-1317).

\section{Methods}

\section{Patients and samples}

In total, 24 patients with glioma, including 12 with astrocytoma and 12 with GBM, were recruited at Nanfang Hospital, Southern Medical University from MAR 2019 to
AUG 2020. All procedures involving human participants were in accordance with principles of the Declaration of Helsinki (2013). All patients signed informed consent, and the study design was approved by the Ethics Committee of Nanfang Hospital (NFEC-2019-006). Tumor tissue and matched normal blood were collected from each patient. Hematoxylin and eosin (HE) stained histological sections of tumors were reviewed by an expert pathologist to ensure that the tumor content was above $20 \%$. Clinical records were obtained from the electronic medical records of the hospital.

\section{WES}

Maxwell RSC blood DNA kit (cat no. AS1400, Promega) was used to extract DNA in snap-frozen tissue and peripheral whole blood, and MagMAX FFPE DNA/RNA Ultra kit (cat no A31881, Thermo Fisher Scientific) was used to extract DNA in formalin-fixed, paraffin-embedded (FFPE) tissue. A Covaris LE220 sonicator was used for shearing with purified DNA. Probes from the SureSelect XT Human All Exon V7 kit (cat. no. 5991-9039, Agilent) were used to hybridize with DNA fragments. After being polymerase chain reaction (PCR)-amplified and endrepaired, captured DNA was attached to the adapters and barcode using a SureSelect XT HS and Low Input Library Preparation Kit for ILM (pre PCR) kit (cat. no. G9704, Agilent). Libraries were sequenced on an Illumina NovaSeq-6000 sequencer (Illumina). The reads were aligned to hg19 after removing adapters and low-quality reads using the Burrows-Wheeler Alignment algorithm and the Genome Analysis Toolkit (GATK, version 3.5).

\section{RNA-seq}

The MagMAX FFPE DNA/RNA Ultra kit (Thermo Fisher Scientific) was used to extract RNA from FFPE tissue. The NEBNext RNA First Strand Synthesis Module [cat. no. E7525S, New England Biolabs Inc. (NEB)] was used for reverse transcription, and the NEBNext Ultra II NonDirectional RNA Second Strand Synthesis Module (cat. no. E6111S, NEB) was used for complement DNA (cDNA) synthesis. SureSelect XT HS and Low Input Library Preparation Kit for ILM (Pre PCR) (cat. no. G9704, Agilent) was used for RNA-seq library preparation. The libraries were sequenced on an NovaSeq-6000 Sequencing System (Illumina, USA). Although it is a difficult to use FFPE samples for RNA-seq, studies have established 
reliable protocols $(11,12)$. NEBNext RNA First Strand Synthesis Module and NEBNext Ultra II Non-Directional RNA second Strand Synthesis Module, 2 commercial kits which were developed from the protocols, were used for RNA-seq in this study.

\section{Differential gene expression analysis}

STAR (version 020201) was used to align the reads to the reference genome (hg19), and StringTie2 (version 1.3.5) was used for assembly. After normalization was completed using upper quartile counts, a list of differentially expressed genes between astrocytoma and GBM was compiled using DESeq2. An adjusted $\mathrm{P}$ value $<0.1$ and an absolute value of $\log 2$ fold change $>1$ was set as the significance threshold.

\section{Immune cell infiltration analysis}

The infiltration of immune cells was analyzed by the CIBERSORT Algorithm with LM22 immune subsets (13). The relative scores of 22 human immune cell types were quantified using 547 marker genes with a genebased deconvolution algorithm. The standardized data set was uploaded to the CIBERSOFT website (https:// cibersort.stanford.edu/index.php) and run using 1,000 aligned default signature matrices.

\section{Statistical analysis}

GraphPad Prism 8 (GraphPad Software, Inc., CA, USA) and R version 4.0.3 (R Foundation for Statistical Computing) were used for statistical analyses and data visualization. Unless stated otherwise, an unpaired $t$-test was used in all group comparisons, and a $\mathrm{P}$ value $<0.05$ was considered significant.

\section{Results}

\section{Clinicopathological and epidemiological information of patients}

Astrocytoma and GBM are the 2 main subtypes of glioma. Exploring the molecular characteristics of these 2 subtypes have a great value for clinical diagnosis and treatment. In this study, 12 patients with GBM and 12 patients with astrocytoma were enrolled and WES and RNA-seq were performed. The overall clinical data of these patients are shown in Table 1 . There were 14 male patients and 10 female patients $(\mathrm{P}=0.214)$. The median age was 45.5 (range, 18-68) years old, with the age of GBM patients being greater than that of astrocytoma patients $(\mathrm{P}=0.048)$. There were 7 patients with $I D H 1$ mutation and 17 patients with IDH1 wild type. Among the patients with IDH1 mutation, there were 6 patients with astrocytoma and only 1 patient with $\mathrm{GBM}(\mathrm{P}=0.068)$, indicating that the majority of $\mathrm{GBM}$ patients in this study had primary GBM. In addition, the methylation of the MGMT promoter and the mutation of the TERT promoter were detected in 24 patients. There were 10 patients with $M G M T$-promoter methylation, 5 of whom had GBM and 5 of whom had astrocytoma $(\mathrm{P}=0.640)$. There were 11 patients with a mutation in the TERT promoter, including 10 patients with GBM and 1 patient with astrocytoma $(\mathrm{P}<0.001)$.

\section{Somatic mutation profile in astrocytoma and GBM}

WES was performed on the 24 patients, and the somatic mutation gene was analyzed. The top 20 mutated genes are shown in Figure 1A. TP53, FRG1, and IDH1 were the top 3 mutated genes in glioma, and their mutation rates were $54 \%(13 / 24)$, $33 \%(8 / 24)$, and 29\% (7/24), respectively. The mutation rates of several genes differed between astrocytoma and GBM. IDH1 mutations were found in 50\% $(6 / 12)$ of astrocytoma cases but in only $8 \%(1 / 12)$ of GBM cases. Usually, the IDH1 mutation of GBM progresses from astrocytoma with the $I D H 1$ mutation, and is called secondary GBM (14). In addition, TP53, KRT18, and ATRX were enriched in astrocytoma, but TTN was enriched in GBM (Figure 1A). Statistical analysis showed that KRT18 was the only gene which was significantly enriched in astrocytoma (Fisher's exact test, $\mathrm{P}=0.037$; Figure $1 B$ ).

Next, we analyzed the mutation sites of the KRT18 gene in the patients; 6 different mutation sites were found in 5 patients with astrocytoma, but none were found in GBM patients. The most frequent mutation was p.S100R, found in 4 out of the 5 patients. The other mutations included p.T103N, p.R106W, p.M84I, p.R90C, and p.A92P (Figure 1C). All the mutation sites were located in the Coil 1A domain [80-115] of the KRT18 gene. Studies have reported that this region is closely related to the interaction of tumor necrosis factor (TNF) receptor 1-associated protein (TRADD) and the pinin protein $(15,16)$. TRADD is a tumor suppressor associated with cell apoptosis, while pinin is involved in the regulation of cell adhesion and modulation of the activity of multiple tumor suppressor genes $(17,18)$. The above results showed that somatic 
Table 1 Characteristics of glioma patients

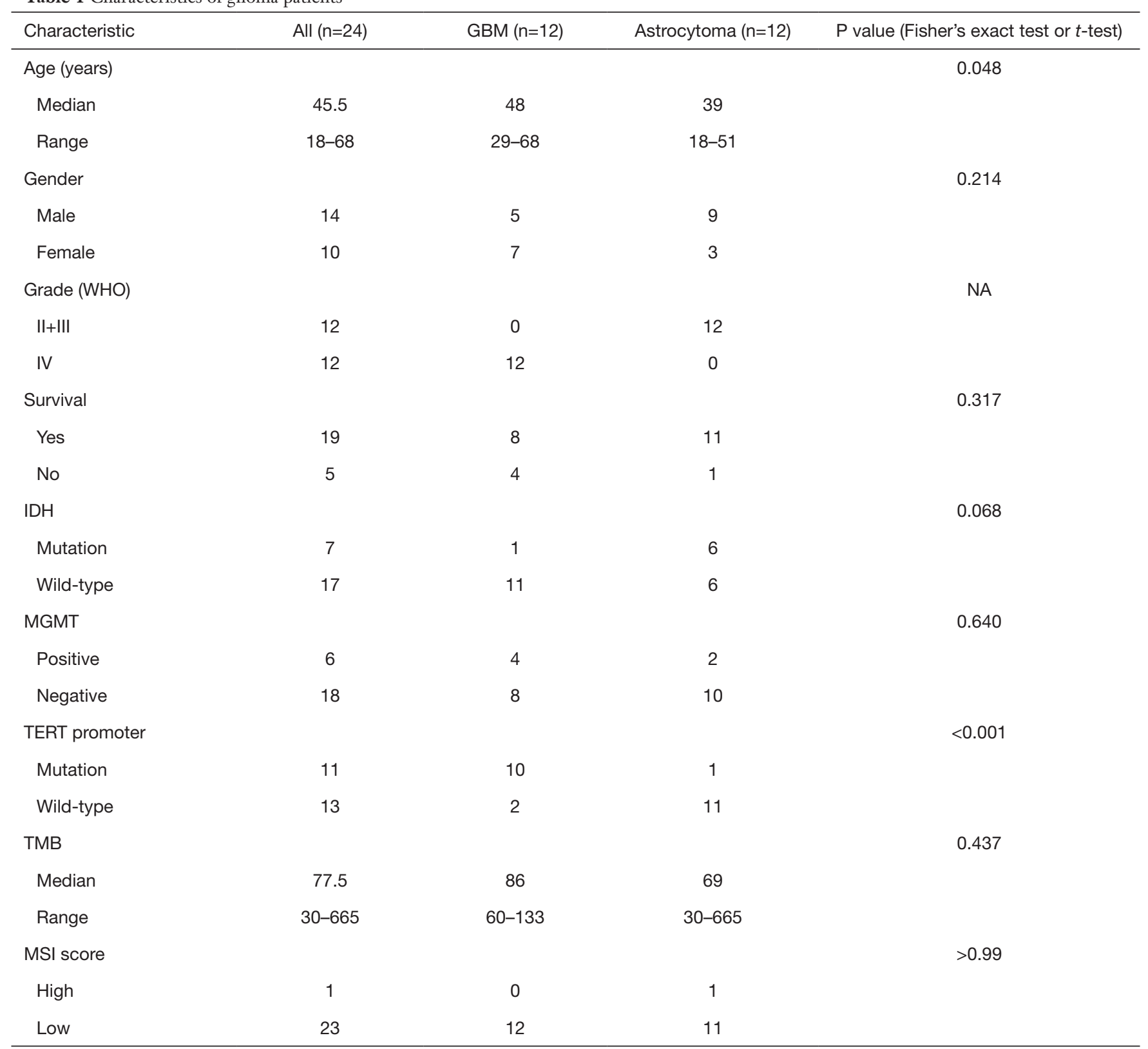

GBM, glioblastoma; WHO, World Health Organization; NA, not applicable; IDH, isocitrate dehydrogenase; MGMT, $\mathrm{O}^{6}$-methylguanine-DNA methyltransferase; TERT, telomerase reverse transcriptase; TMB, tumor mutational burden; MSI, microsatellite instability.

mutation of KRT18 gene in astrocytoma may affect the apoptosis and adhesion of glioma cells.

\section{Copy number variations (CNVs) in astrocytoma and GBM}

A CNV is a type of duplication or deletion event that affects a large stretch of base pairs. We analyzed the copy number amplification or deletion of genes in the patients. The results revealed amplification at HIST1H3E, HIST1H4I, $B R D 3, I N H B A, R X R A$, and SETD 3 loci, and deletions at KIF20B, MTAP, CDK1, PTEN, and BIRC2 loci (Figure 2A). Copy number loss of $M T A P$ was the only event significantly enriched in GBM (Fisher's exact test, $\mathrm{P}=0.014$; Figure $2 B$ ). To verify this result, we analyzed the frequency of the copy number loss of MTAP in astrocytoma and GBM by using The Cancer Genome Atlas Low Grade Glioma (TCGA- 
A

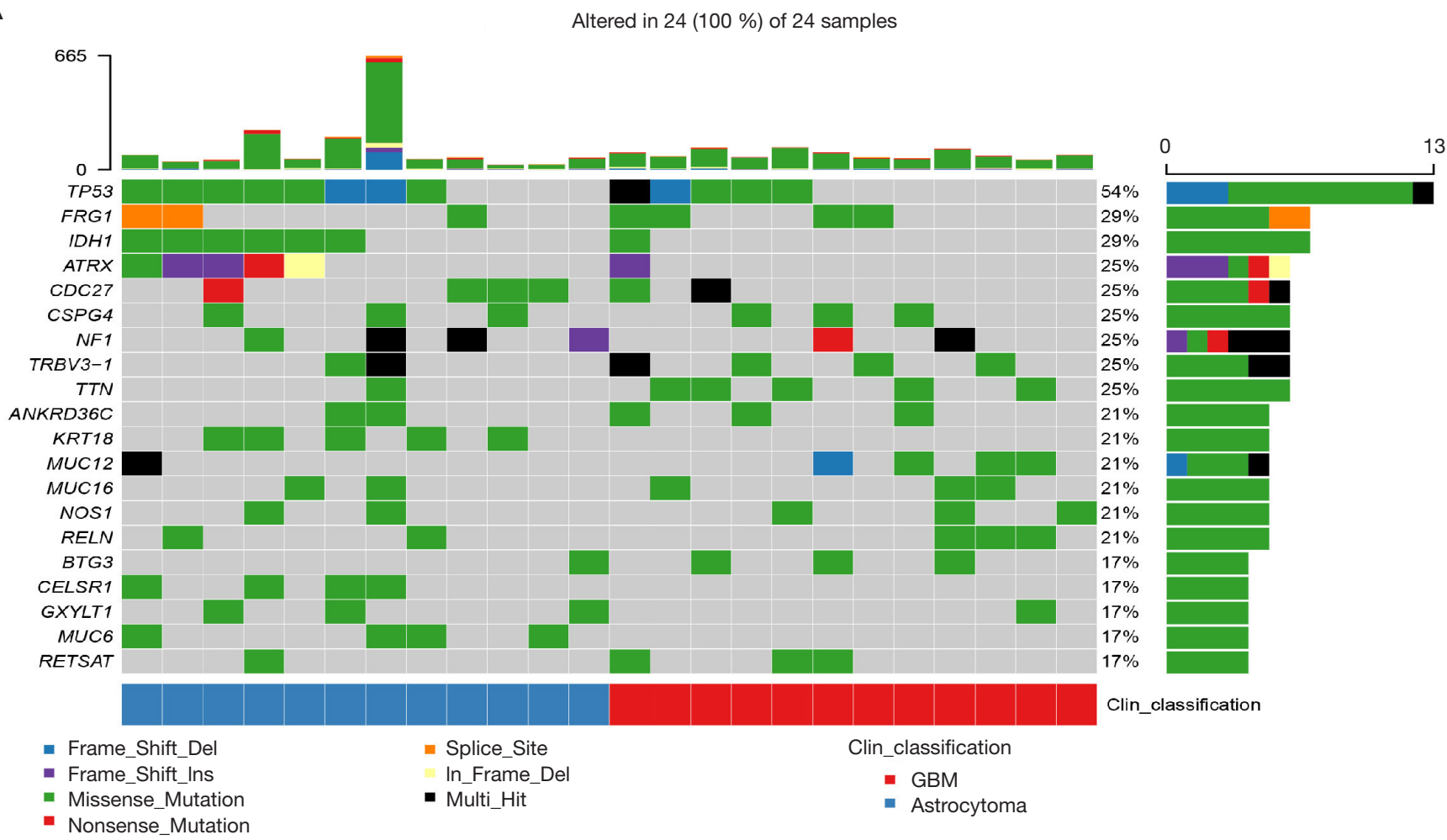

B

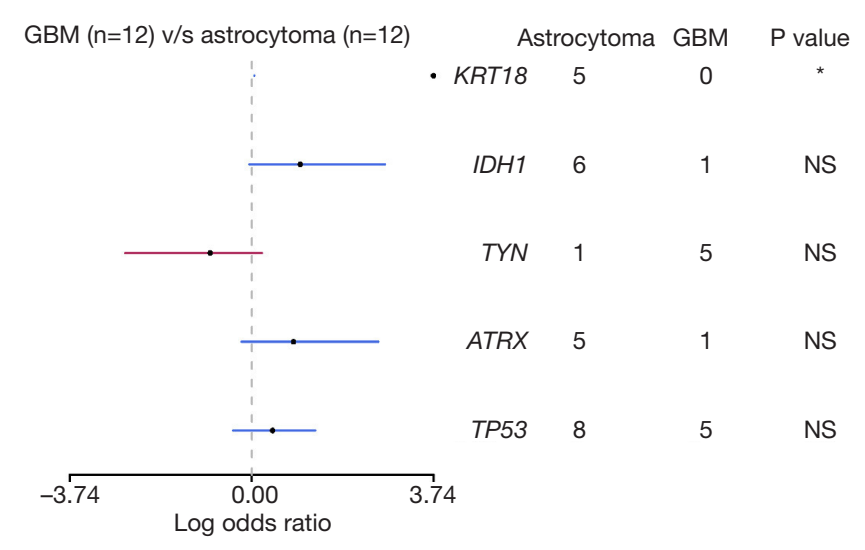

C

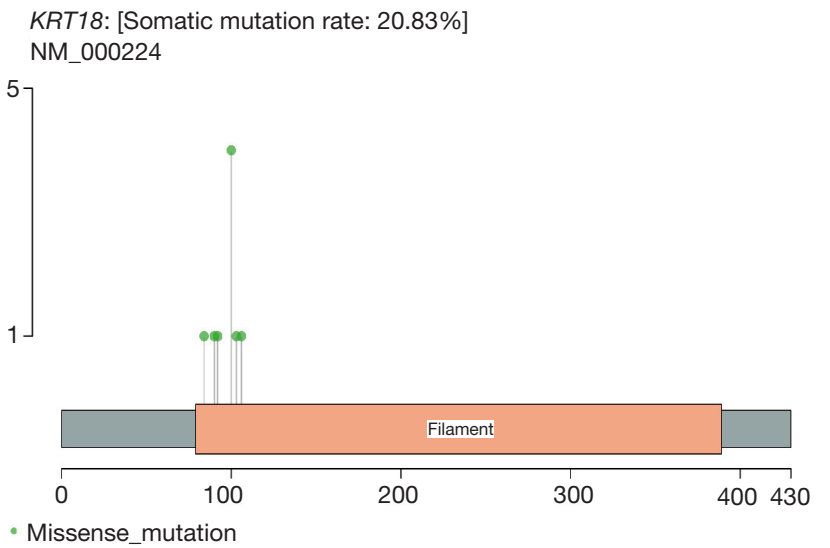

Figure 1 Genetic mutation profile in astrocytoma and GBM. (A) Overview of the top 20 mutated genes in astrocytoma and GBM. (B) Forest graph of differentially mutated genes between astrocytoma and GBM. The dots and horizontal bars represent the hazard rate and 5-95\% CI. (Fisher's exact test; *: P<0.05). (C) Hot spots of mutations in the KRT18 gene. GBM, glioblastoma. 
A

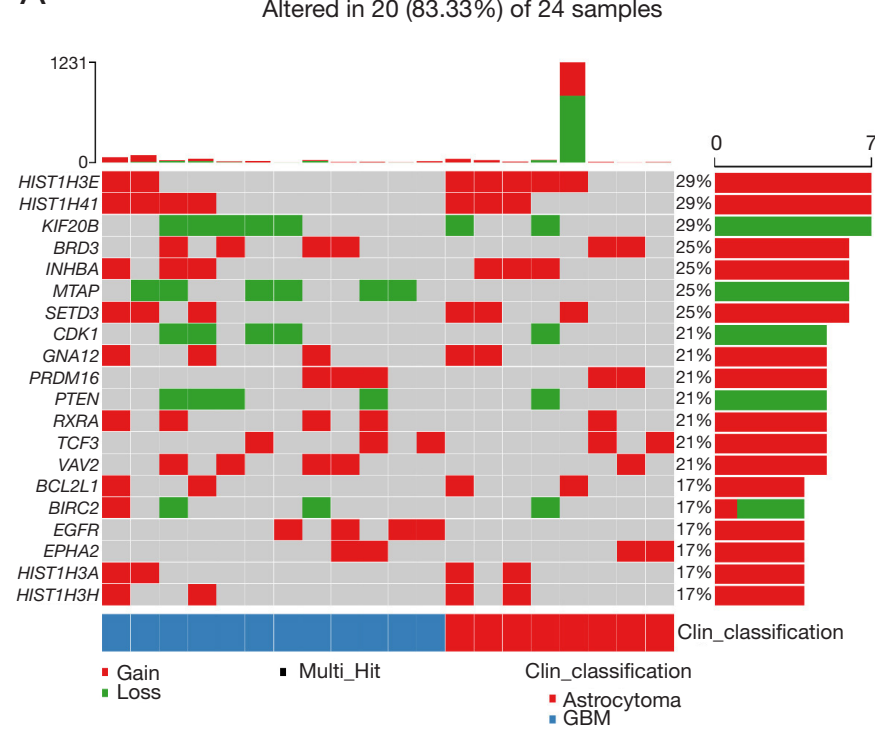

C

Astrocytoma (TCGA-LGG, $\mathrm{n}=193$ )

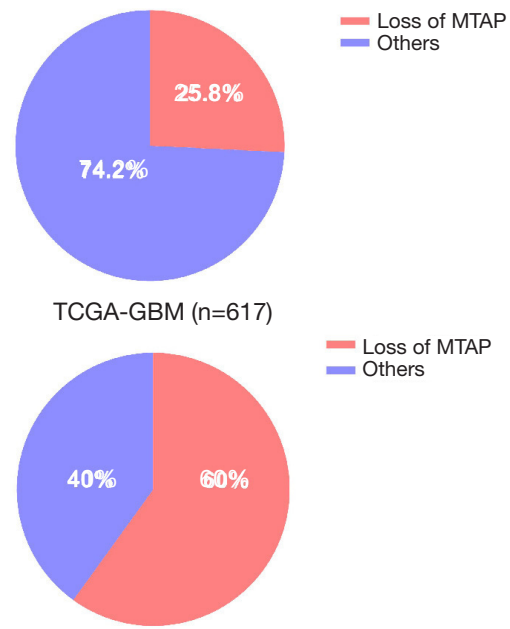

B

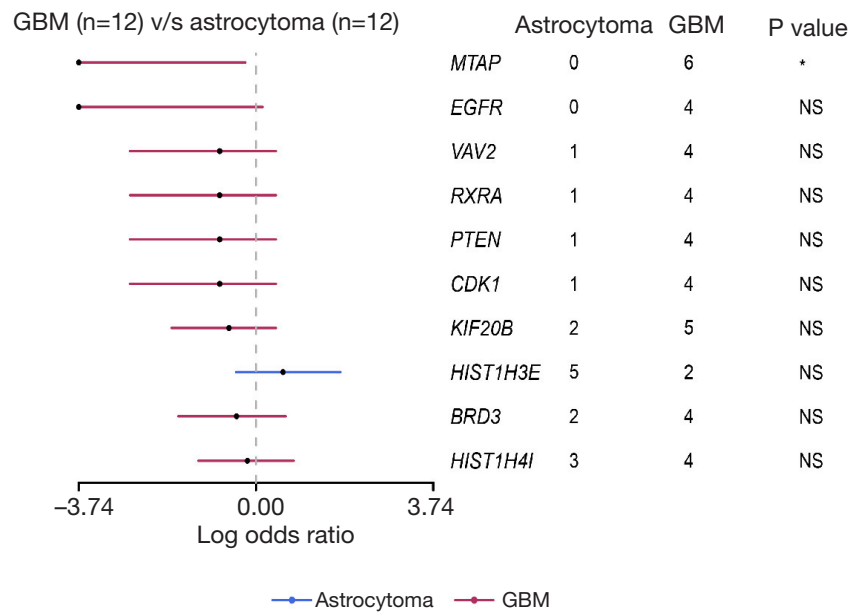

$\mathrm{D}$

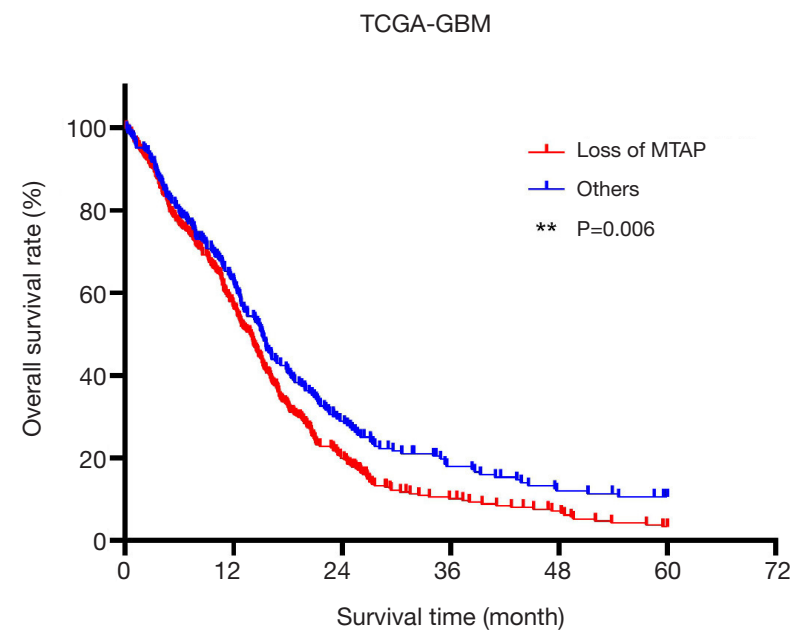

Figure 2 Differential copy number variations between astrocytoma and GBM. (A) Overview of the top 20 genes with CNVs. (B) Forest graph of CNVs between astrocytoma and GBM. The dots and horizontal bars represent the hazard rate and 5-95\% CI. (Fisher's exact test, *: P<0.05). (C) The proportion of patients with copy number loss of MTAP in astrocytoma and GBM in TCGA database. The 193 patients with astrocytoma were from TCGA-LGG cohort, and the 617 patients with GBM were from TCGA-GBM cohort. (D) Survival of patients with GBM in TCGA-GBM cohort analyzed by the Kaplan-Meier method. The red line represents patients with copy number loss of MTAP. The blue line represents patients with no CNVs of MTAP. The clinical and genetic data were downloaded from TCGA database. **, $\mathrm{P}<0.01$. GBM, glioblastoma; CNVs, copy number variations. 
LGG) data and TCGA-GBM data. Results showed that $25.8 \%$ of TCGA patients with astrocytoma have copy number loss of the MTAP gene, but the proportion reached $60 \%$ in GBM (Figure 2C). This was consistent with the results of our study. We further analyzed the prognosis of patients from the TCGA-GBM data set. Results showed that the survival time of patients with copy number loss of the MTAP gene was shorter than that in other patients $(\mathrm{P}=0.006$; Figure 2D). These results suggested that MTAP may be a tumor suppressor gene and that loss of MTAP is closely related to a poor prognosis in glioma.

\section{Differential patterns of somatic copy number alterations (SCNAs) in astrocytoma and GBM}

To further analyze the SCNAs in the astrocytoma and GBM patients, GISTIC2.0 was used to detect SCNA. In the astrocytoma patients, 2 amplification peaks were found at cytobands $9 \mathrm{q} 34.11$ and $13 \mathrm{q} 14$, and several regions of chromosomal loss were found at cytobands $14 \mathrm{q} 32.33$, 11p15.5, 19p13.3, and 21q22.3 (Figure 3A). Meanwhile, no amplification peak was found in the GBM patients, and only 1 region of chromosomal loss at 9p21.3 was discovered, which includes several tumor suppressor genes, such as $M T A P, C D K N 2 A$, and, $C D K N 2 B$ (Figure $3 B$ ). An earlier study reported that low $C D K N 2 B$ expression and loss of 9 p21.3 were associated with worse prognosis in GBM (19). Taken together, these results indicated that the SCNA pattern differs between astrocytoma and GBM.

\section{Differential signal pathway enrichment in astrocytoma and $G B M$}

To explore the differences in the transcriptome between astrocytoma and GBM, RNA-seq was performed in the 24 patients. Principal component analysis (PCA) showed that astrocytoma and GBM had distinct gene expression profiles (PC1 =22\%, PC2 =18\%; Figure 4A). Differentially expressed genes were analyzed using DESeq2, and the significance threshold was set at adjusted $\mathrm{P}$ value $<0.1$ with an absolute value of $\log 2$ fold change $(\log \mathrm{FC})>1$ (Figure 4B). Gene Ontolgoy (GO) biological process analysis was performed in upregulated genes and downregulated genes, and the top 10 pathways are shown in Figure $4 C, D$. The results showed that the upregulated genes in GBM were mainly enriched in tumor-related pathways, such as cell adhesion, cell division, and angiogenesis (Figure 4C). However, the upregulated genes in astrocytoma were mainly enriched in pathways of ion transport, cell-cell signaling, and neurogenesis (Figure 4D). The above results indicated that GBM may have higher cell proliferation and invasion ability when compared with astrocytoma.

\section{$R N A$-seq revealed differentially expressed genes between astrocytoma and GBM}

A total of 1,242 genes were upregulated and 812 genes were downregulated in GBM when compared with astrocytoma. A heatmap was constructed to show the top 50 differentially expressed genes (Figure $5 A$ and Table S1). RELN was the most significantly enriched gene in astrocytoma when compared with GBM $[\log \mathrm{FC}=5.08$ (astrocytoma over GBM); adjusted $\mathrm{P}$ value $=7.38 \mathrm{e}-09$; Figure $5 \mathrm{~A}$ and Table $\mathrm{S} 1]$. RELN encodes a large secreted extracellular matrix protein which regulates the cell positioning and neuronal migration during brain development (20). It can modulate the growth and substrate-dependent migration of glioma cells (21), with downregulation of RELN predicting a poor prognosis in glioma (22).

In addition, we analyzed the differentially expressed genes which were upregulated in GBM, with OTP being found to be the highest rank gene $[\log \mathrm{FC}=5.78$ (GBM over astrocytoma); adjusted $\mathrm{P}$ value $=1.66 \mathrm{e}-09$; Figure $5 \mathrm{~A}$ and Table S1]. It is involved in brain development and is a prognostic hypoxia-associated gene in IDH-mutant glioma (23). CCL18, a small cytokine of the CC chemokine family, was highly expressed in GBM when compared with astrocytoma $(\log \mathrm{FC}=5.08$, adjusted $\mathrm{P}$ value $=8.88 \mathrm{e}-07$; Figure $5 A$ and Table S1). It is produced and secreted mainly by the innate immune system (24). Studies have found that CCL18 is highly expressed in glioma and other CNS patients with traumatic brain injuries or neoplastic disorders $(25,26)$, and that CCL18 is an immune-related risk signature for GBM and can promote the invasion of GBM cells (27).

We further found several genes associated with cell migration and proliferation, including $M M P 7, M M P 9$, $I G F B P 2$, and IGGBP3. These results were consistent with the characteristics of GBM that are presented in Figure $4 C$. Cumulatively, these findings indicated that astrocytoma and GBM have distinct gene expression patterns.

Our results above (Figure 2) showed that copy number loss of the MTAP gene was significantly enriched in GBM, but was absent in astrocytoma. It would be of interest to see whether its expression is consistent with the copy number alterations obtained from the WES data. Indeed, the expression of MTAP in GBM obtained from RNA-seq was 

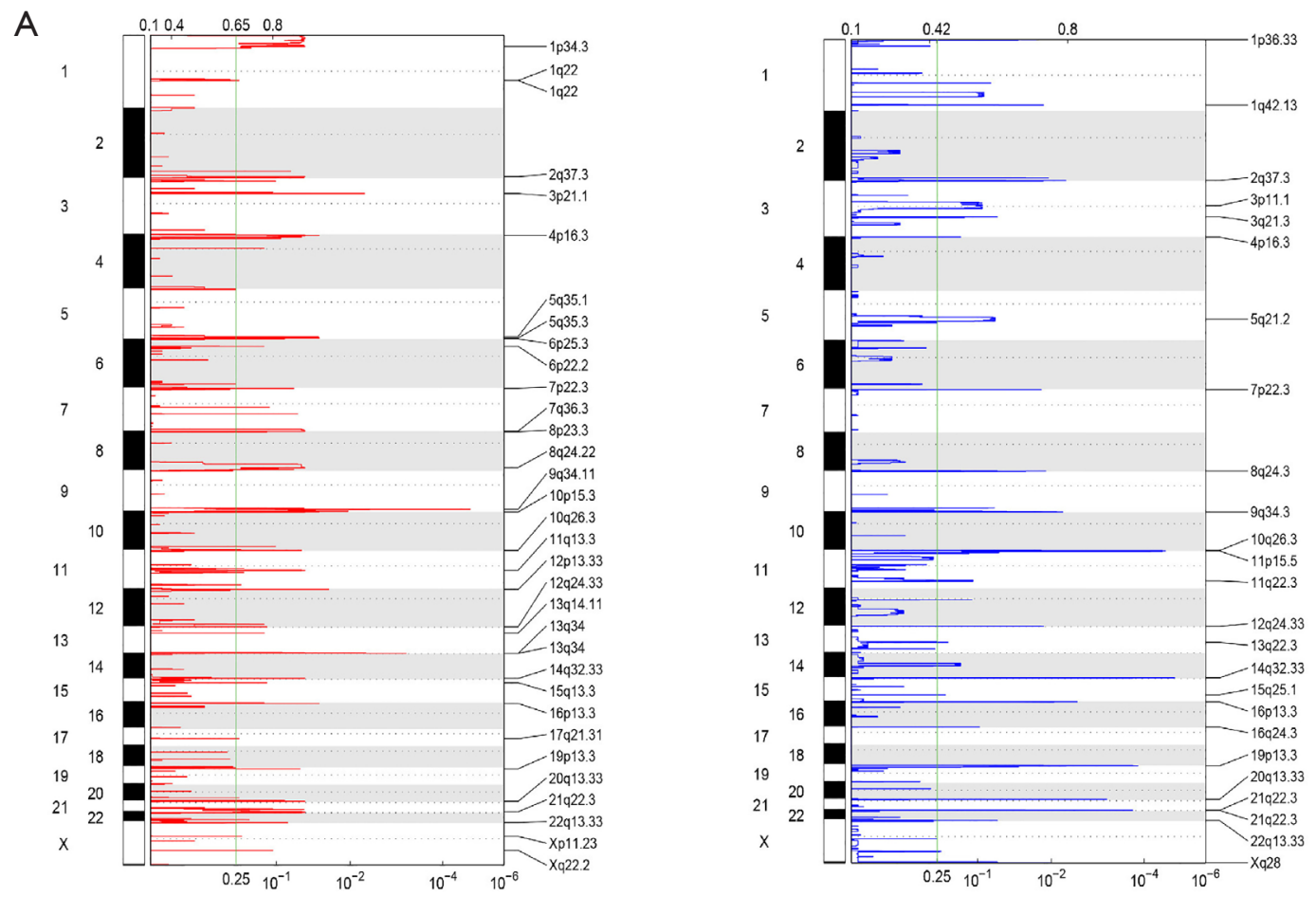

B
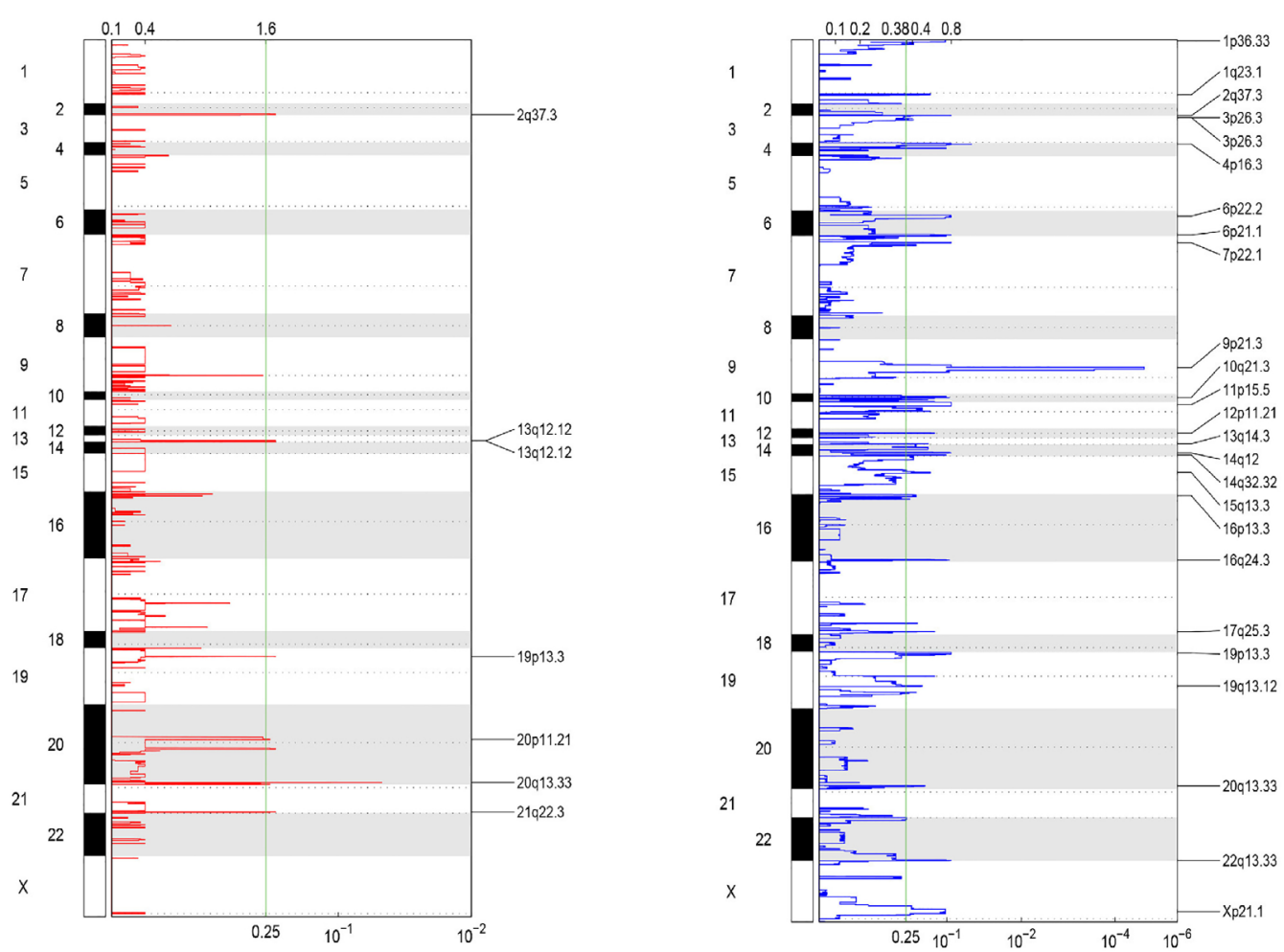

Figure 3 Different patterns of SCNA in astrocytoma and GBM. Amplification (left, red) and deletion (right, blue) in astrocytoma (A) and GBM (B) were analyzed using GISTIC 2.0. The left y-axes represent the number of chromosomes, and the right y-axes represent the genomic position of altered regions. The top $x$-axes represent the normalized amplification signal, and the bottom $x$-axes represent the significance by $Q$ value. The significance cutoff of $Q$ value $(0.25)$ is indicated by the green line. SCNA, somatic copy number alteration; GBM, glioblastoma. 
A

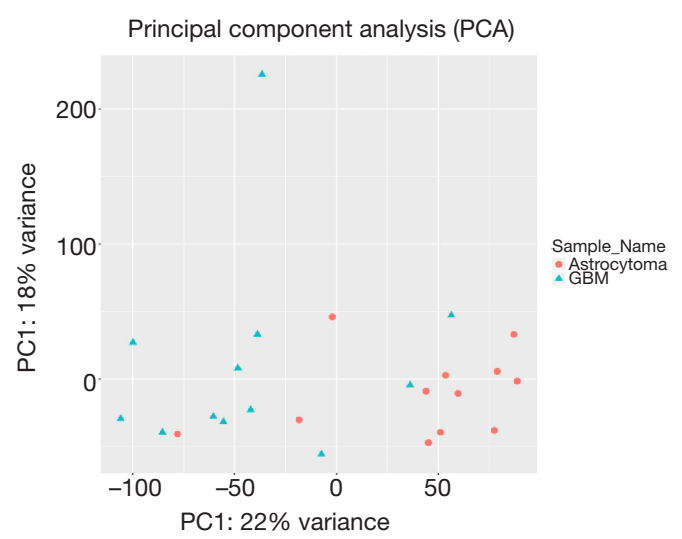

C

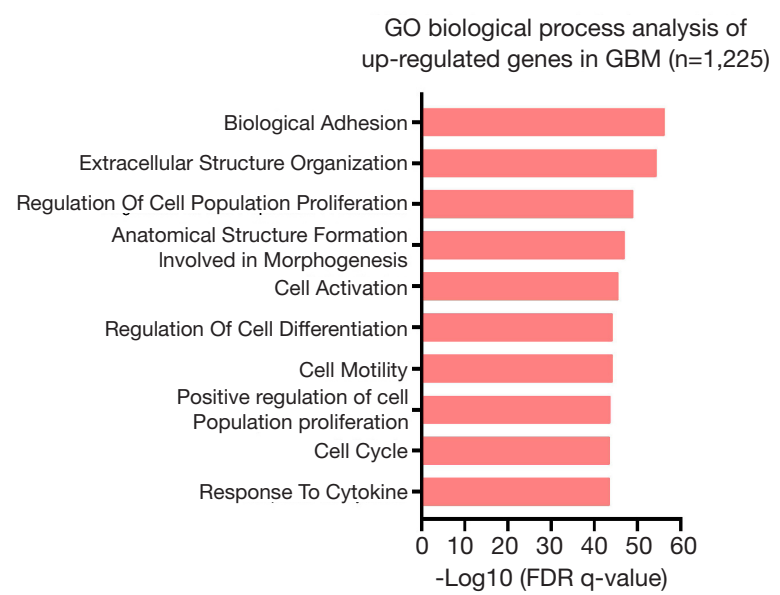

B

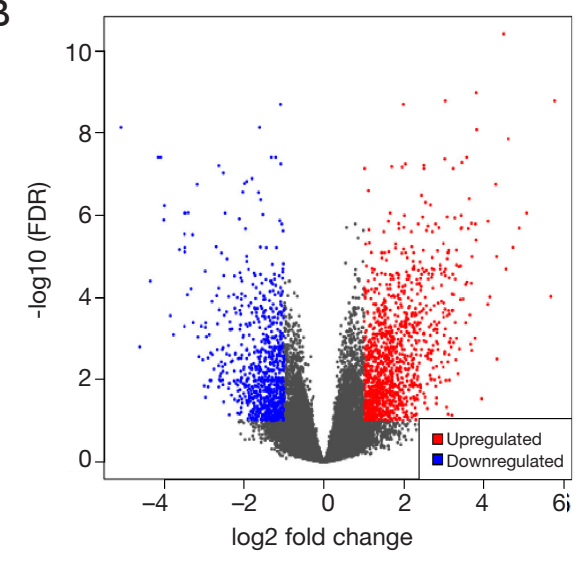

D

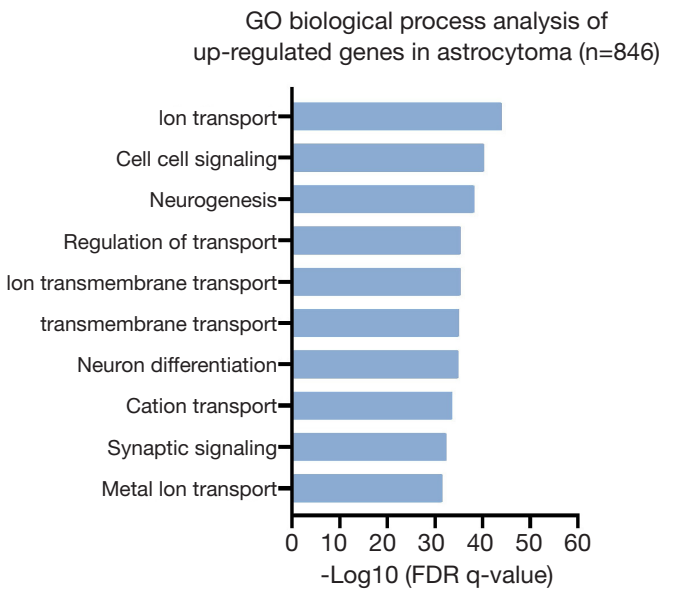

Figure 4 Differential pathways between astrocytoma and GBM. (A) Principal component analysis was performed in astrocytoma and GBM. The blue dots represent the sample of GBM, and the red dots represent the sample of astrocytoma. (B) Differentially expressed genes (GBM vs. astrocytoma) were analyzed by DESeq2. The upregulated (Log2 fold change $\geq 1, \operatorname{FDR}<0.1$ ) and downregulated (Log2 fold change $\leq-1$, FDR $<0.1)$ genes were selected and are displayed with a volcano map. The red dots represent the upregulated genes that met the thresholds, and the blue dots represent the downregulated genes that met the thresholds. (C) GO biological process analysis of upregulated genes in GBM. The top10 pathways are shown with red bars. (D) GO biological process analysis of upregulated genes in astrocytoma. The top 10 pathways are shown with blue bars. GBM, glioblastoma; GO, Gene Ontolgoy.

significantly lower than that in astrocytoma (Figure $5 B$ ). We also analyzed the expression of KRT18 in astrocytoma and GBM but found no difference between the two (Figure 5C).

\section{Infiltration of immune cells in astrocytoma and GBM}

Immune checkpoint inhibitors (ICIs) have become an area of intense research in glioma, but the objective response rate of ICIs in glioma is only about $10 \%$. Tumor microenvironment (TME) may be one of the more important factors which affect the response to ICIs. Therefore, CIBERSORT was used to analyze the RNAseq data and assess the infiltration of 22 immune cell types in the tumor microenvironment of the patients (13). The results showed that most immune cell types, including cluster of differentiation (CD) $8^{+} \mathrm{T}$ cells, B cells, CD $4^{+}$ $\mathrm{T}$ cells, and M1 macrophages, were missing from the microenvironment of the patients (Figure $6 A$ and Table S2). Although M2 macrophages were enriched in the TME, there was no significant difference between astrocytoma 
A

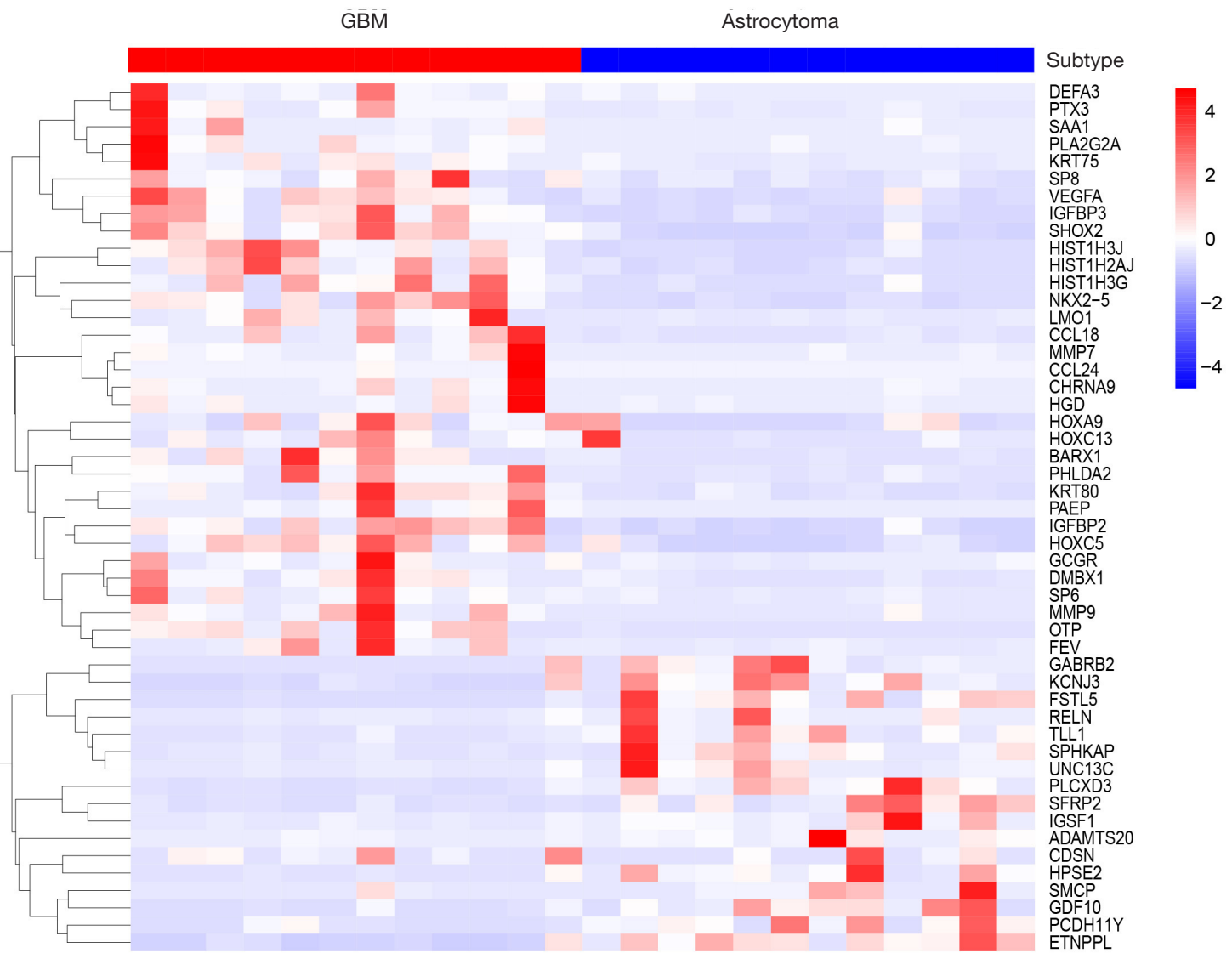

B

C
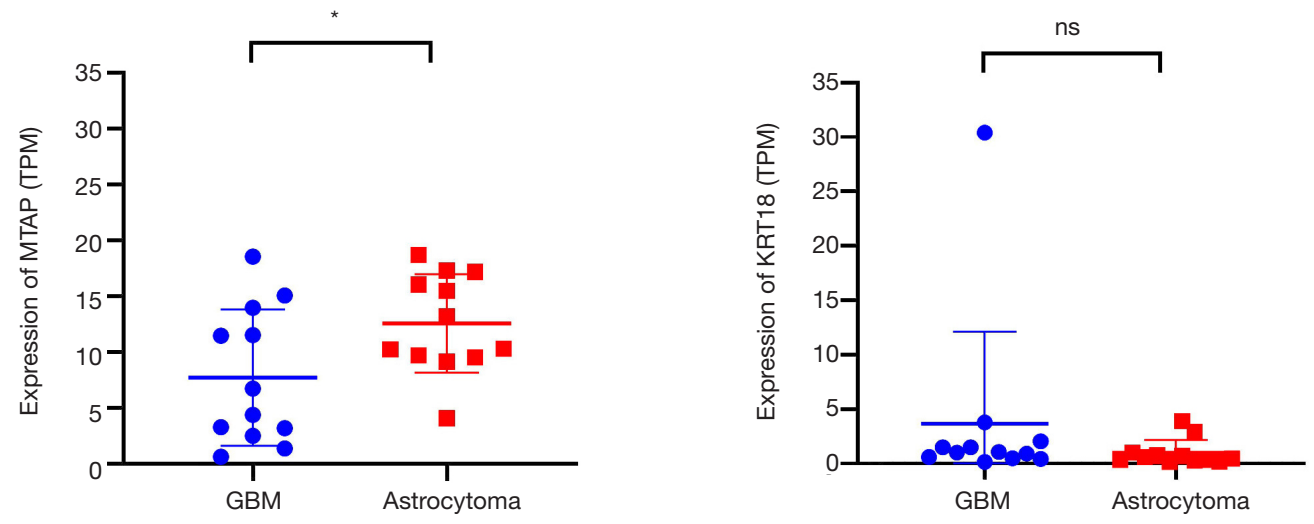

Figure 5 Differentially expressed genes between astrocytoma and GBM. (A) A heatmap showing the top 50 differentially expressed genes between astrocytoma and GBM. One column represents one sample, and one row represents one gene. (B,C) The expression of MTAP gene (B) and KRT18 gene (C) in astrocytoma and GBM from RNA-seq. *, $\mathrm{P}<0.05$; "ns" means no significance. GBM, glioblastoma. 


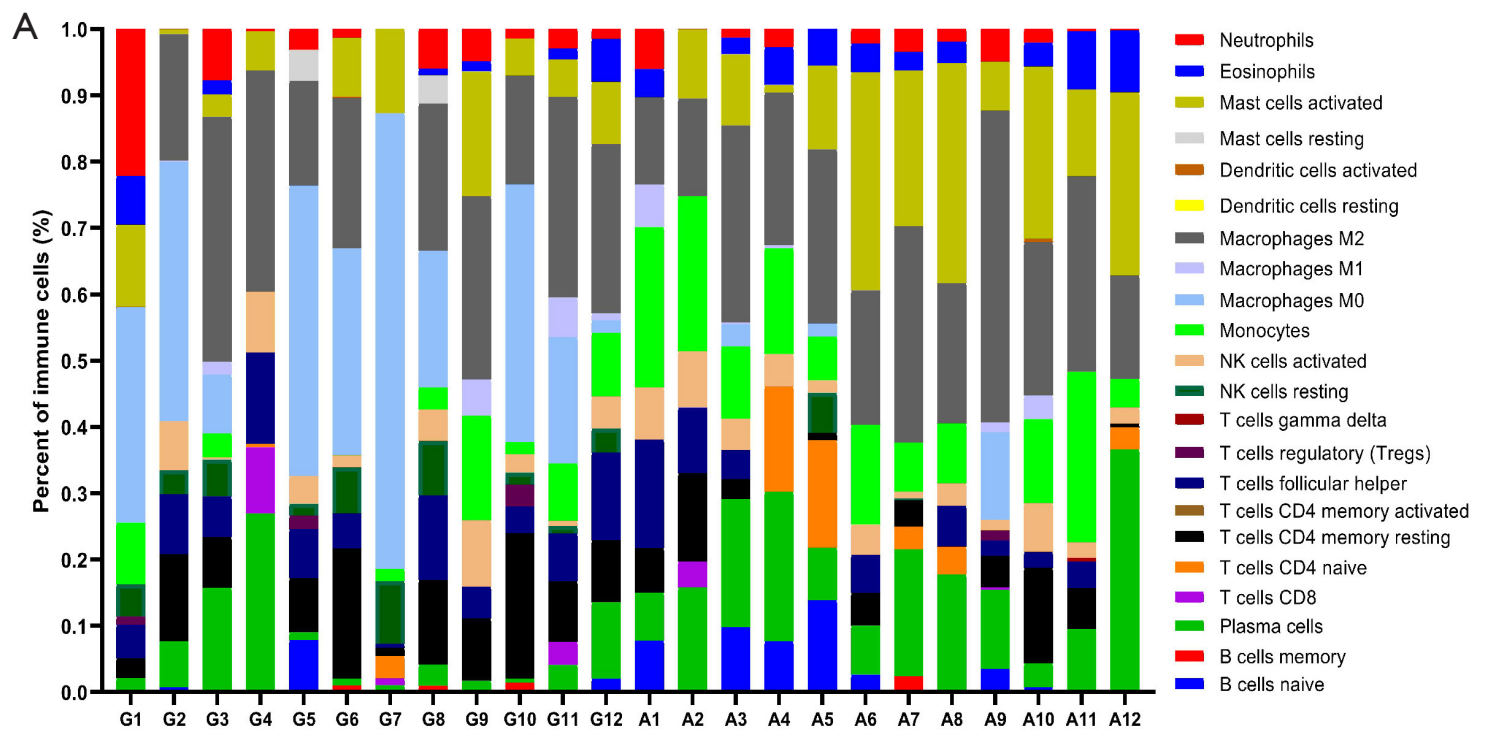

B

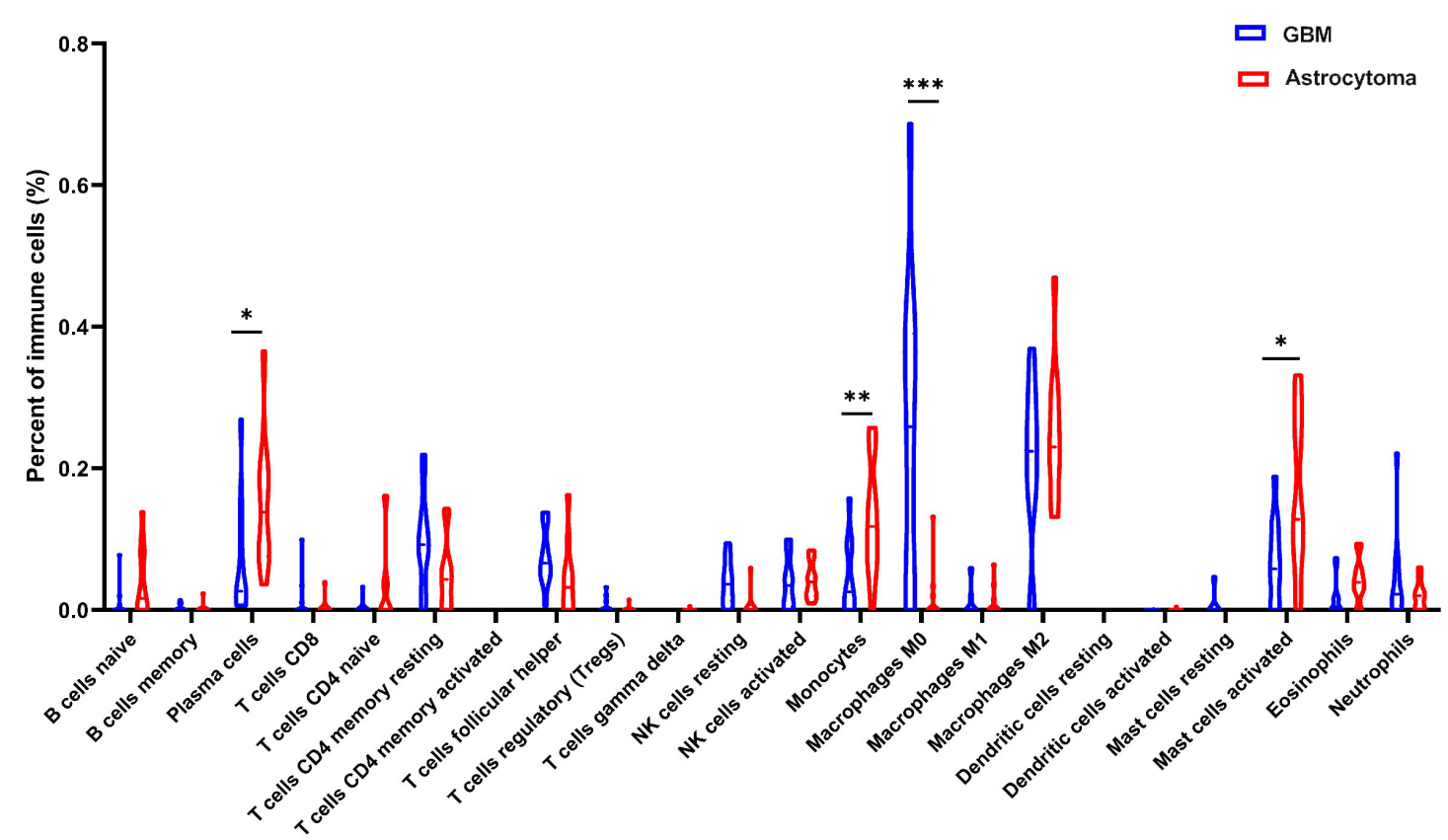

Figure 6 Immune cell infiltration analysis in astrocytoma and GBM. (A) Infiltration of immune cells in astrocytoma and GBM was analyzed by CIBERSORT with LM22 immune subsets. The percentages of 22 immune cells in every sample are shown with stacking bars. "G" represents the samples of GBM, and "A" represents the samples of astrocytoma. (B) Comparison of the infiltration of immune cells between astrocytoma and GBM. Immune cells with significantly differences are marked. * $\mathrm{P}<0.05 ;{ }^{* *}, \mathrm{P}<0.01 ;{ }^{* * *}, \mathrm{P}<0.001$. GBM, glioblastoma.

and GBM (Figure 6B). However, we found that M0 macrophages were significantly enriched in GBM, while activated mast cells, monocytes, and plasma cells were significantly enriched in astrocytoma (Figure 6B). These immune cells may closely relate to the formation of the microenvironment in astrocytoma and GBM.

\section{Discussion}

According to the histologic criteria of CNS WHO (2016), 
DA is categorized as grade II, and AA is categorized as grade III (2). However, multiple studies have shown that diffuse or AA with $I D H$ wild type has an aggressive clinical course and poor prognosis, similar to patients with $I D H$ wildtype GBM $(9,28,29)$. The classification and grading of $I D H$ wildtype astrocytoma may not accurately reflect the molecular pathogenesis and clinical outcomes of this tumor type. Therefore, cIMPACT-NOW (the Consortium to Inform Molecular and Practical Approaches to CNS Tumor Taxonomy) convened a working committee and released cIMPACT-NOW update 3, 5, and 6 (30-32). According to cIMPACT-NOW update 3, IDH wild-type DA patients with EGFR amplification, or combined whole chromosome 7 gain and whole chromosome 10 loss, or TERT promoter mutation, should be considered WHO grade IV GBM (30). In this study, 6 patients with the $I D H$ wild-type astrocytoma were found, and one of them also had a TERT promoter mutation. However, due to the lack of corresponding treatment guidelines for the patients with $I D H$ wild-type astrocytoma, CNS WHO (2016) was still used as the main reference for diagnosis and classification in this study.

The KRT18 gene encodes type I intermediate filament chain keratin 18, which can provide the support for the cytoskeleton (33). The full-length fragment of KRT18 has been proposed to be used as a biomarker of liver damage (34). However, its function in glioma is still unknown. In this study, we found that somatic mutation of the KRT18 gene was significantly enriched in astrocytoma, but it was not found in GBM (42\% vs. $0 \%)$. Furthermore, we found that all mutation sites of KRT18 in astrocytoma were located in the Coil 1A domain, which is the core region for the interaction of KRT18 with the TRADD and pinin proteins. TRADD is a tumor suppressor whose overexpression can lead to TNF-induced apoptosis and activation of nuclear factor (NF)-kappa-B (35). Moreover, it is also a direct regulator of cellular homeostasis, whose targeting may represent a promising strategy for restoring homeostasis to treat human diseases (17). Pinin is a nuclear and cell adhesion-related phosphoprotein, and its reduction can induce loss of cell-cell adhesion (36). It can bind to the transcriptional corepressor C-terminal binding protein $(\mathrm{CtBP})$ and relieve $\mathrm{CtBP}$-mediated repression of E-cadherin (18). Our results in this study indicate that the somatic mutation of KRT18 may affect its interaction with the TRADD protein and pinin protein, and change the apoptosis and adhesion of glioma cells. However, this notion needs to be verified by further experimentation.

$\mathrm{CNV}$ is another important molecular feature of glioma.
In this study, we found that loss of MTAP was the most significant difference between astrocytoma and GBM. The MTAP gene is located at 9p21.3, which encodes 5 '-methylthioadenosine phosphorylase, and plays a major role in polyamine metabolism (37). MTAP deletion frequently occurs in tumors, but its biological role in glioma remains unclear. Our analysis of the TCGA-GBM data suggested that loss of MTAP was associated with the poor prognosis of GBM. A study reported that loss of MTAP immunoreactivity can be used as a biomarker to predict the poor prognosis of glioma (38). MTAP loss could promote the stemness of GBM and confer a unique susceptibility to purine starvation (39). These studies indicated that MTAP may be a tumor suppressor gene in glioma. However, the pathologic consequence of MTAP loss in GBM remains unclear and need to further study.

ICIs have been approved for the treatment of multiple solid tumors. However, due to the inherent obstacles, such as the blood-brain barrier, tumor microenvironment, corticosteroids, and tumor heterogeneity, ICIs have limited therapeutic benefits for patients with glioma. An effective biomarker may improve the response of patients to ICIs. However, we found that, except for a few patients, it has a very low level of tumor mutational burden (TMB), microsatellite instability (MSI), and programmed deathligand 1 (PD-L1) in glioma. We analyzed the infiltration of immune cells in the astrocytoma and GBM patients using the CIBERSORT Algorithm but found almost no obvious infiltration of $\mathrm{CD} 8^{+} \mathrm{T}$ cells, B cells, $\mathrm{CD} 4^{+} \mathrm{T}$ cells, or M1 macrophages. This indicated an immunosuppressive microenvironment. M2 macrophages were enriched in the TME of patients, but no significant difference was found between astrocytoma and GBM. A study reported that transforming growth factor beta 1 (TGF- $\beta 1$ ) secreted by M2 macrophages could enhance the stemness and migration of glioma cells through the SMAD2/3 signaling pathway (40). Another study found that glioma patients with lower expression of the M2 marker, CD163, and higher expression of the M1 marker, CCL3, had better survival (41). These studies suggest that M2 macrophages are likely to be a common immune cell between astrocytoma and GBM, and closely related to tumorigenesis.

In addition, we also found a significant enrichment of M0 macrophages in GBM when compared with astrocytoma. Studies have shown that high-risk glioma populations usually have enrichment of M0 macrophages (42), and the infiltration of $\mathrm{M} 0$ macrophages is related to the poor prognosis of glioma (43). This is consistent with the poor 
prognosis of GBM. In the astrocytoma patients, we found significant enrichment of activated mast cells, monocytes, and plasma cells. Mast cells play an important role in allergies and allergic reactions (44). They can suppress the proliferation, migration, and stemness of glioma by downregulating the expression of GSK3 $\beta$ and inhibiting STAT3 activation (45). Monocytes are mononuclear myeloid cells that develop in bone marrow and circulate in the blood (46). The infiltration of monocytes has been shown to be positively related to prognosis in patients with glioma (43), and tends to be exhausted in patients with recurrent GBM (47). These studies suggest that the infiltration of immune cells in astrocytoma may be associated with its better prognosis compared to GBM.

In summary, we found that the somatic mutation of KRT18, which is associated with cell apoptosis and adhesion through interaction with TRADD and pinin, was significantly enriched in astrocytoma, but rare in GBM. Copy number loss of MTAP, which is closely related to the poor prognosis of glioma, was found to be significantly enriched in GBM. In addition, different SCNA and gene expression patterns between astrocytoma and GBM were also found. Furthermore, immune cell infiltration analysis showed that M0 macrophages were significantly enriched in GBM, while activated mast cells, monocytes, and plasma cells were significantly enriched in astrocytoma. This study revealed the distinct characteristics of astrocytoma and GBM at the DNA and RNA level, and may have an important value for exploring the occurrence of glioma.

\section{Acknowledgments}

Funding: None.

\section{Footnote}

Reporting Checklist: The authors have completed the ARRIVE reporting checklist. Available at http://dx.doi. org/10.21037/atm-21-1317

Data Sharing Statement: Available at http://dx.doi. org/10.21037/atm-21-1317

Conflicts of Interest: All authors have completed the ICMJE uniform disclosure form (available at http://dx.doi. org/10.21037/atm-21-1317). The authors have no conflicts of interest to declare.
Ethical Statement: The authors are accountable for all aspects of the work in ensuring that questions related to the accuracy or integrity of any part of the work are appropriately investigated and resolved. All procedures involving human participants were in accordance with principles of the Declaration of Helsinki (2013). All patients signed informed consent, and the study design was approved by the Ethics Committee of Nanfang Hospital (NFEC2019-006).

Open Access Statement: This is an Open Access article distributed in accordance with the Creative Commons Attribution-NonCommercial-NoDerivs 4.0 International License (CC BY-NC-ND 4.0), which permits the noncommercial replication and distribution of the article with the strict proviso that no changes or edits are made and the original work is properly cited (including links to both the formal publication through the relevant DOI and the license). See: https://creativecommons.org/licenses/by-nc-nd/4.0/.

\section{References}

1. Ostrom QT, Cioffi G, Gittleman H, et al. CBTRUS Statistical Report: Primary Brain and Other Central Nervous System Tumors Diagnosed in the United States in 2012-2016. Neuro-Oncol 2019;21:v1-100.

2. Louis DN, Perry A, Reifenberger G, et al. The 2016 World Health Organization Classification of Tumors of the Central Nervous System: a summary. Acta Neuropathol 2016;131:803-20.

3. Ghosh D, Nandi S, Bhattacharjee S. Combination therapy to checkmate Glioblastoma: clinical challenges and advances. Clin Transl Med 2018;7:33.

4. Azzarelli R. Organoid Models of Glioblastoma to Study Brain Tumor Stem Cells. Front Cell Dev Biol 2020;8:220.

5. van den Bent MJ, Smits M, Kros JM, et al. Diffuse Infiltrating Oligodendroglioma and Astrocytoma. J Clin Oncol 2017;35:2394-401.

6. Ohgaki $\mathrm{H}$, Kleihues $\mathrm{P}$. The definition of primary and secondary glioblastoma. Clin Cancer Res 2013;19:764-72.

7. Ajlan A, Recht L. Supratentorial low-grade diffuse astrocytoma: medical management. Semin Oncol 2014;41:446-57.

8. Grimm SA, Chamberlain MC. Anaplastic astrocytoma. CNS Oncol 2016;5:145-57.

9. Hartmann C, Hentschel B, Wick W, et al. Patients with IDH1 wild type anaplastic astrocytomas exhibit worse 
prognosis than IDH1-mutated glioblastomas, and IDH1 mutation status accounts for the unfavorable prognostic effect of higher age: implications for classification of gliomas. Acta Neuropathol 2010;120:707-18.

10. Weller M, van den Bent M, Tonn JC, et al. European Association for Neuro-Oncology (EANO) guideline on the diagnosis and treatment of adult astrocytic and oligodendroglial gliomas. Lancet Oncol 2017;18:e315-29.

11. Cieslik M, Chugh R, Wu YM, et al. The use of exome capture RNA-seq for highly degraded RNA with application to clinical cancer sequencing. Genome Res 2015;25:1372-81.

12. Karn T, Meissner T, Weber KE, et al. A Small Hypoxia Signature Predicted pCR Response to Bevacizumab in the Neoadjuvant GeparQuinto Breast Cancer Trial. Clin Cancer Res 2020;26:1896-904.

13. Newman AM, Liu CL, Green MR, et al. Robust enumeration of cell subsets from tissue expression profiles. Nat Methods 2015;12:453-7.

14. Parsons DW, Jones S, Zhang X, et al. An integrated genomic analysis of human glioblastoma multiforme. Science 2008;321:1807-12.

15. Inada H, Izawa I, Nishizawa $M$, et al. Keratin attenuates tumor necrosis factor-induced cytotoxicity through association with TRADD. J Cell Biol 2001;155:415-26.

16. Shi J, Sugrue SP. Dissection of protein linkage between keratins and pinin, a protein with dual location at desmosome-intermediate filament complex and in the nucleus. J Biol Chem 2000;275:14910-5.

17. Xu D, Zhao H, Jin M, et al. Modulating TRADD to restore cellular homeostasis and inhibit apoptosis. Nature 2020;587:133-8.

18. Alpatov R, Munguba GC, Caton P, et al. Nuclear SpeckleAssociated Protein Pnn/DRS Binds to the Transcriptional Corepressor CtBP and Relieves CtBP- Mediated Repression of the E-Cadherin Gene. Mol Cell Biol 2004;24:10223-35.

19. Feng J, Kim ST, Liu W, et al. An integrated analysis of germline and somatic, genetic and epigenetic alterations at 9p21.3 in glioblastoma. Cancer 2012;118:232-40.

20. Honda T, Kobayashi K, Mikoshiba K, et al. Regulation of cortical neuron migration by the Reelin signaling pathway. Neurochem Res 2011;36:1270-9.

21. Schulze M, Violonchi C, Swoboda S, et al. RELN signaling modulates glioblastoma growth and substratedependent migration. Brain Pathol 2018;28:695-709.

22. Li X, Fan W, Yao A, et al. Downregulation of reelin predicts poor prognosis for glioma. Biomark Med
2020;14:651-63.

23. Dao Trong P, Rösch S, Mairbäurl H, et al. Identification of a Prognostic Hypoxia-Associated Gene Set in IDHMutant Glioma. Int J Mol Sci 2018;19:2903.

24. Korbecki J, Olbromski M, Dzięgiel P. CCL18 in the Progression of Cancer. Int J Mol Sci 2020;21:7955.

25. Chang CY, Lee YH, Leu SJ, et al. CC-chemokine ligand 18/pulmonary activation-regulated chemokine expression in the CNS with special reference to traumatic brain injuries and neoplastic disorders. Neuroscience 2010;165:1233-43.

26. Ma L, Wang H, Li Z, et al. Chemokine (C-C motif) ligand 18 is highly expressed in glioma tissues and promotes invasion of glioblastoma cells. J Cancer Res Ther 2019;15:358-64.

27. Cheng W, Ren X, Zhang C, et al. Bioinformatic profiling identifies an immune-related risk signature for glioblastoma. Neurology 2016;86:2226-34.

28. Weller M, Weber RG, Willscher E, Riehmer V, Hentschel B, Kreuz M, et al. Molecular classification of diffuse cerebral WHO grade II/III gliomas using genome- and transcriptome-wide profiling improves stratification of prognostically distinct patient groups. Acta Neuropathol 2015;129:679-93.

29. Cancer Genome Atlas Research Network; Brat DJ, Verhaak RG, et al. Comprehensive, Integrative Genomic Analysis of Diffuse Lower-Grade Gliomas. N Engl J Med 2015;372:2481-98.

30. Brat DJ, Aldape K, Colman H, et al. cIMPACT-NOW update 3: recommended diagnostic criteria for 'Diffuse astrocytic glioma, IDH-wildtype, with molecular features of glioblastoma, WHO grade IV'. Acta Neuropathol 2018;136:805-10.

31. Brat DJ, Aldape K, Colman H, et al. cIMPACT-NOW update 5: recommended grading criteria and terminologies for IDH-mutant astrocytomas. Acta Neuropathol 2020;139:603-8.

32. Louis DN, Wesseling P, Aldape K, et al. cIMPACTNOW update 6: new entity and diagnostic principle recommendations of the cIMPACT-Utrecht meeting on future CNS tumor classification and grading. Brain Pathol 2020;30:844-56.

33. Wang PB, Chen Y, Ding GR, et al. Keratin 18 induces proliferation, migration, and invasion in gastric cancer via the MAPK signalling pathway. Clin Exp Pharmacol Physiol 2020. [Epub ahead of print]. doi: 10.1111/14401681.13401.

34. Dear JW, Clarke JI, Francis B, et al. Risk stratification 
after paracetamol overdose using mechanistic biomarkers: results from two prospective cohort studies. Lancet Gastroenterol Hepatol 2018;3:104-13.

35. Hsu H, Xiong J, Goeddel DV. The TNF receptor 1-associated protein TRADD signals cell death and NFkappa B activation. Cell 1995;81:495-504.

36. Joo JH, Alpatov R, Munguba GC, et al. Reduction of Pnn by RNAi induces loss of cell-cell adhesion between human corneal epithelial cells. Mol Vis 2005;11:133-42.

37. Zhang T, Bauer C, Newman AC, et al. Polyamine pathway activity promotes cysteine essentiality in cancer cells. Nat Metab 2020;2:1062-76.

38. Satomi K, Ohno M, Matsushita Y, et al. Utility of methylthioadenosine phosphorylase immunohistochemical deficiency as a surrogate for CDKN2A homozygous deletion in the assessment of adult-type infiltrating astrocytoma. Mod Pathol 2021;34:688-700.

39. Hansen LJ, Sun R, Yang R, et al. MTAP Loss Promotes Stemness in Glioblastoma and Confers Unique Susceptibility to Purine Starvation. Cancer Res 2019;79:3383-94.

40. Liu Z, Kuang W, Zhou Q, et al. TGF- $\beta 1$ secreted by M2 phenotype macrophages enhances the stemness and migration of glioma cells via the SMAD2/3 signalling pathway. Int J Mol Med 2018;42:3395-403.

Cite this article as: $\mathrm{Li}$ Z, Jin $\mathrm{Y}$, Zou Q, Shi $\mathrm{X}, \mathrm{Wu} \mathrm{Q}$, Lin Z, He Q, Huang G, Qi S. Integrated genomic and transcriptomic analysis suggests KRT18 mutation and MTAP are key genetic alterations related to the prognosis between astrocytoma and glioblastoma. Ann Transl Med 2021;9(8):713. doi: 10.21037/atm-21-1317
41. Vidyarthi A, Agnihotri T, Khan N, et al. Predominance of M2 macrophages in gliomas leads to the suppression of local and systemic immunity. Cancer Immunol Immunother 2019;68:1995-2004.

42. Zhu C, Zou C, Guan G, et al. Development and validation of an interferon signature predicting prognosis and treatment response for glioblastoma. Oncoimmunology 2019;8:e1621677.

43. Zhong QY, Fan EX, Feng GY, et al. A gene expressionbased study on immune cell subtypes and glioma prognosis. BMC Cancer 2019;19:1116.

44. Nelissen S, Lemmens E, Geurts N, et al. The role of mast cells in neuroinflammation. Acta Neuropathol 2013;125:637-50.

45. Attarha S, Roy A, Westermark B, et al. Mast cells modulate proliferation, migration and stemness of glioma cells through downregulation of GSK $3 \beta$ expression and inhibition of STAT3 activation. Cell Signal 2017;37:81-92.

46. Mitchell AJ, Roediger B, Weninger W. Monocyte homeostasis and the plasticity of inflammatory monocytes. Cell Immunol 2014;291:22-31.

47. Wang Q, Hu B, Hu X, et al. Tumor Evolution of GliomaIntrinsic Gene Expression Subtypes Associates with Immunological Changes in the Microenvironment. Cancer Cell 2017;32:42-56.e6. 
$\begin{array}{lllll}\text { ENSG000000171540 } & 5.771921 & 1.66 \mathrm{E}-09 & \text { OTP } & \text { 5q14.1 }\end{array}$

$\begin{array}{lllll}\text { ENSG600000188257 } & 5.67735 & 9.50 E-05 & \text { PLA2G2A } & 1 \text { 1p36.13 }\end{array}$

$\begin{array}{lllll}\text { ENSG000000275385 } & 5.076155 & 8.88 E-07 & \text { CCL18 } & 17912\end{array}$

ENSG00000131668 $\quad 4.893882 \quad 2.07 E-06 \quad$ BARX1 9922.32 $\begin{array}{lllll}\text { ENSG600000137673 } & 4.737592 & 6.12 E-06 & \text { MMP7 } & 11922.2\end{array}$

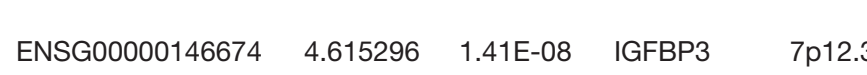
ENSG00000137197 $4.552285 \quad 2.04 E-05 \quad$ CDSN $\begin{array}{llll}\text { ENSG000000183072 } & 4.492517 & 3.938-11 & \text { NKX2-5 }\end{array}$ ENSG000000106178 $4.326043 \quad 3.14 E-03 \quad$ CCL24 $\begin{array}{lllll}\text { ENSG600000170454 } & 4.318729 & 1.02 E-05 & \text { KRT75 } & 12913.13\end{array}$ ENSG00000173432 $4.295869 \quad 1.79 E-07 \quad$ SAA1 $\quad 11$ 1p15.1 ENSG000000174343 4.148618 9.68E-05 $\quad$ CHRNA9 4 4P14 $\begin{array}{lllll}\text { ENSG00000197587 } & 4.103129 & 1.40 E-06 & \text { DMBX1 } & 1 \text { p33 }\end{array}$ $\begin{array}{lllll}\text { ENSGG00000163497 } & 4.098435 & 1.48 E-04 & \text { FEV } & 2935\end{array}$ $\begin{array}{lllll}\text { ENSGG00000239839 } & 3.943858 & 2.92 E-02 & \text { DEFA3 } & 8 \text { 8223.1 }\end{array}$ $\begin{array}{lllll}\text { ENSG000000115457 } & 3.823131 & 8.35 E-09 & \text { IGFBP2 } & 2935\end{array}$ $\begin{array}{lllll}\text { ENSG00000197153 } & 3.809606 & 1.05 E-09 & \text { HIST1H3J } & \text { 6р22.1 }\end{array}$ $\begin{array}{lllll}\text { ENSG00000167767 } & 3.805729 & 4.06 E-06 & \text { KRT80 } & 12913.13\end{array}$ $\begin{array}{lllll}\text { ENSG00000113924 } & 3.791455 & 1.63 \mathrm{E}-06 & \text { HGD } & 3913.33\end{array}$ ENSG00000100985 $\begin{array}{llll}3.781975 & 9.78 E-04 & \text { MMP9 } & 20913.12\end{array}$ $\begin{array}{lllll}\text { ENSG00000168779 } & 3.70592 & 1.03 E-05 & \text { SHOX2 } & 3925.32\end{array}$ $\begin{array}{lllll}\text { ENSG00000122133 } & 3.700063 & 1.94 E-03 & \text { PAEP } & 9934.3\end{array}$ $\begin{array}{llllr}\text { ENSG00000163661 } & 3.692964 & 1.566-06 & \text { PTX3 } & 3 q 25.32\end{array}$ ENSG00000215644 $3.689396 \quad 4.544-05$ GCGR $\quad 17925.3$ ENSG00000078399 $3.672813 \quad 1.37 \mathrm{E}-03 \quad$ HOXA9 $\quad 7$ p15.2 $\begin{array}{lllll}\text { ENSG00000164651 } & 3.654028 & 2.67 \mathrm{E}-04 & \text { SP8 } & 7 \mathrm{P} 21.1\end{array}$ $\begin{array}{lllll}\text { ENSG00000181649 } & 3.637655 & 3.97 E-07 & \text { PHLDA2 } & 11115.4\end{array}$ ENSG00000166407 $3.614048 \quad 2.13 E-06 \quad$ LMO1 $\quad 111515.4$ ENSG00000172789 $3.581079 \quad 4.26 \mathrm{E}-05$ HOXC5 12913.13

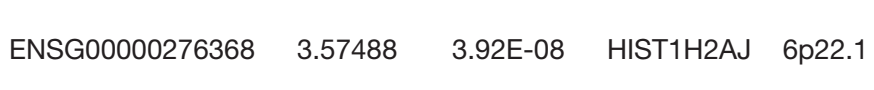
$\begin{array}{lllll}\text { ENSG00000123364 } & 3.55023 & 4.13 E-04 & \text { HOXC13 } & 12913.13\end{array}$ $\begin{array}{lllll}\text { ENSGO00000273983 } & 3.548979 & 4.87 E-05 & \text { HISTHH3G } & \text { 6p22.2 }\end{array}$ $\begin{array}{lllll}\text { ENSGG00000189120 } & 3.485314 & 1.10 E-04 & \text { SP6 } & 17921.32\end{array}$ $\begin{array}{lllll}\text { ENSG000000112715 } & 3.455764 & 5.23 E-08 & \text { VEGFA } & 6021.1\end{array}$ $\begin{array}{lllll}\text { ENSG000000189056 } & -5.0795 & 7.38 E-09 & \text { RELN } & 7922.1\end{array}$

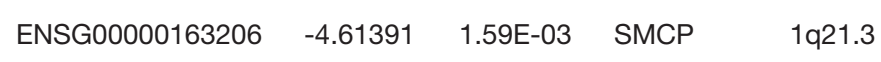
$\begin{array}{lllll}\text { ENSGG00000099715 } & -4.35176 & 4.01 E-05 & \text { PCDH11Y } & \text { Yp1 11.2 }\end{array}$ $\begin{array}{lllll}\text { ENSG00000153820 } & -4.15629 & 3.92 E-08 & \text { SPHKAP } & 2936.3\end{array}$ ENSG00000182836 $\quad-4.09173 \quad 3.92 E-08$ PLCXD3 $\quad 5$ 5p13.1 $\begin{array}{lllll}\text { ENSG600000168843 } & -4.0157 & 1.31 E-06 & \text { FSTL5 } & 4932.2\end{array}$ $\begin{array}{lllll}\text { ENSG00000145864 } & -4.00144 & 5.87 E-07 & \text { GABRB2 } & 5934\end{array}$ ENSG00000137766 $-3.3 .53996 \quad 2.79 E-04 \quad$ UNC13C $\quad 15921.3$ $\begin{array}{lllll}\text { ENSG000000172987 } & -3.77607 & 8.06 E-04 & \text { HPSE2 } & 10024.2\end{array}$ $\begin{array}{lllll}\text { ENSG600000164089 } & -3.62824 & 6.87 E-06 & \text { ETNPPL } & 4925\end{array}$ $\begin{array}{lllll}\text { ENSG00000162989 } & -3.49956 & 8.900-07 & \text { KCNN3 } & 2924.1\end{array}$ $\begin{array}{lllll}\text { ENSG600000173157 } & -3.49654 & 5.03 E-04 & \text { ADAMTS20 } & 12912\end{array}$ $\begin{array}{lllll}\text { ENSGG00000145423 } & -3.49433 & 2.88 E-06 & \text { SFRP2 } & 4931.3\end{array}$ $\begin{array}{lllll}\text { ENSG000000266524 } & -3.48606 & 7.82 E-06 & \text { GDF10 } & 10911.22\end{array}$ ENSG000000038295 $\quad-3.484469 \quad 6.18 E-06$ TLL1 4932.3 $\begin{array}{lllll}\text { ENSG000000147255 } & -3.46994 & 8.90 E-07 & \text { IGSF1 } & \text { Xa26.2 }\end{array}$ $\begin{array}{llllllllllllllllllllllllll}\text { Type } & \text { G1 } & \text { G2 } & \text { G3 } & \text { G4 } & \text { G5 } & \text { G6 } & \text { G7 } & \text { G8 } & \text { G9 } & \text { G10 } & \text { G11 } & \text { G12 } & \text { A1 } & \text { A2 } & \text { A3 } & \text { A4 } & \text { A5 } & \text { A6 } & \text { A7 } & \text { A8 } & \text { A9 } & \text { A10 } & \text { A11 } & \text { A12 }\end{array}$

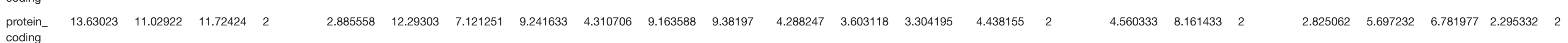

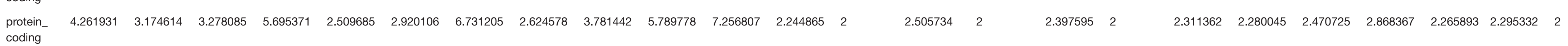

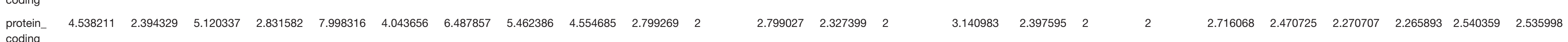

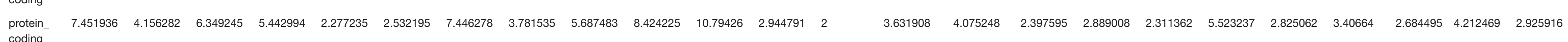
$\begin{array}{lllllllllllllllllllllllll}\begin{array}{l}\text { protein_- } \\ \text { coding }\end{array} & 14.36851 & 12.24219 & 11.11142 & 7.22431 & 11.52642 & 12.19541 & 14.04757 & 11.51804 & 13.14433 & 11.98951 & 11.80288 & 7.419739 & 7.392819 & 5.355664 & 5.706324 & 6.668623 & 9.626268 & 7.848159 & 6.214676 & 3.728936 & 10.20414 & 8.26477 & 4.87984 & 4.626221\end{array}$ _HSCHR6- protein

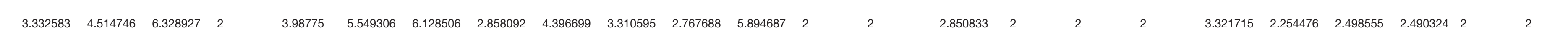
$\begin{array}{llllllllllllllllllllllllll}7.017164 & 6.800028 & 6.720717 & 3.49526 & 7.336562 & 3.356958 & 8.27438 & 7.452826 & 8.385033 & 8.961353 & 6.009401 & 4.5836443 & 2.594069 & 3.304195 & 3.589215 & 4.357561 & 3.187675 & 2.567309 & 3.192445 & 4.030846 & 4.358389 & 2.2658993 & 2.932567 & 3.364464\end{array}$

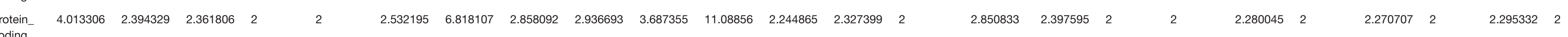

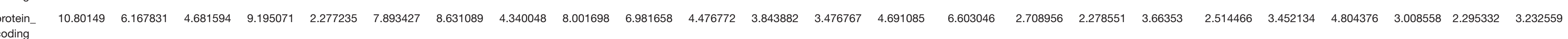

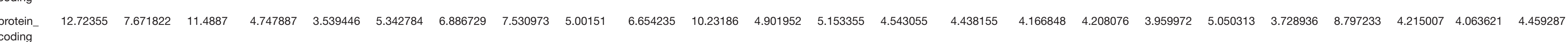
$\begin{array}{lllllllllllllllllllllllll}\text { protein__ } & 9.251217 & 7.430299 & 5.697264 & 4.955469 & 2.277235 & 6.818327 & 9.90592 & 5.351899 & 9.557639 & 7.40077 & 12.24213 & 3.767555 & 2.819053 & 4.737235 & 5.873834 & 3.537972 & 2.8890008 & 4.128393 & 3.746984 & 2.658745 & 7.605201 & 6.913737 & 3.806877 & 2.292749\end{array}$

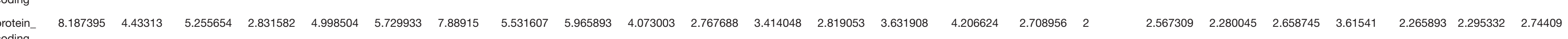

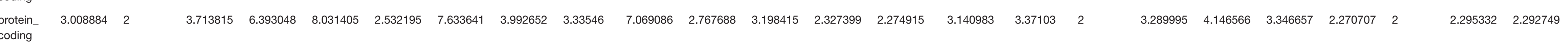

\section{$\begin{array}{llllllllllllllllllllllll}4.822552 & 2 & 2 & 2 & 2.277235 & 2.290499 & 4.432288 & 2.858092 & 2.383731 & 2 & 3.038302 & 2.244865 & 2.594069 & 2 & 2.487251 & 2 & 2 & 2 & 2 & 2 & 2 & 2 & 2 & 2\end{array}$} $\begin{array}{llllllllllllllllllllllll}12.51356 & 11.94883 & 12.66228 & 10.34345 & 12.80782 & 10.58748 & 13.54442 & 13.38554 & 13.63359 & 12.7765 & 13.64244 & 7.796226 & 9.357899 & 5.325771 & 10.08637 & 6.455654 & 8.644342 & 7.576838 & 8.279757 & 8.391427 & 10.9642 & 9.091617 & 6.49703 & 6.21318\end{array}$

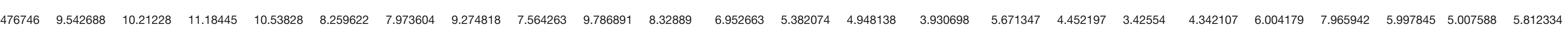

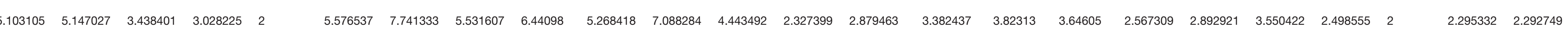
$\begin{array}{llllllllllllllllllllllllll}8.918434 & 6.288768 & 8.371641 & 4.747887 & 4.202195 & 5.063693 & 7.92222 & 5.721328 & 9.156751 & 6.339544 & 11.681 & 5.408584 & 4.020409 & 6.083564 & 5.356247 & 5.597633 & 4.799775 & 4.709336 & 4.214734 & 4.541656 & 6.113159 & 5.308116 & 4.68975 & 4.270389\end{array}$

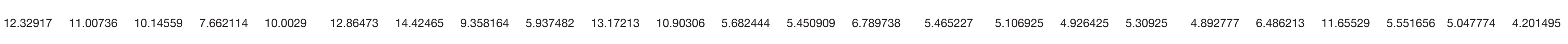

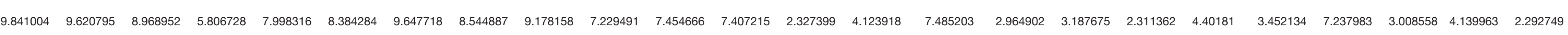

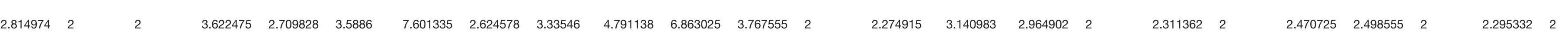

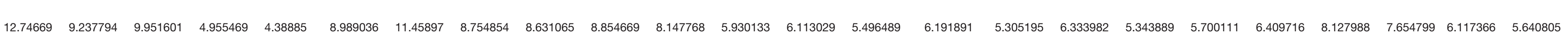

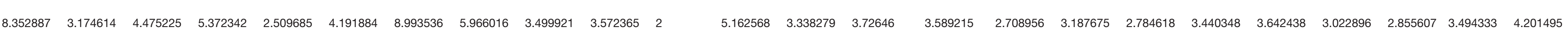

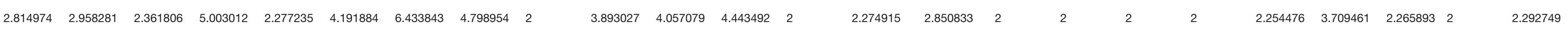

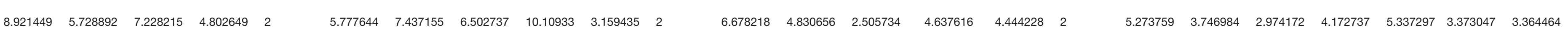
$\begin{array}{llllllllllllllllllllllll}6.83727 & 6.192843 & 6.287413 & 4.042133 & 9.322958 & 5.629502 & 8.56562 & 6.413864 & 6.399923 & 6.303943 & 9.441489 & 4.174616 & 3.185071 & 3.176026 & 4.727876 & 4.265354 & 4.273087 & 3.66353 & 4.279825 & 3.346657 & 5.828786 & 4.978364 & 3.4943333 & 2.292749\end{array}$

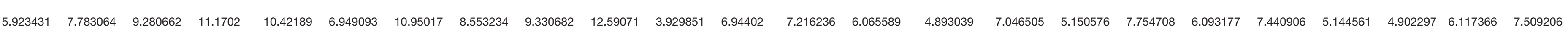

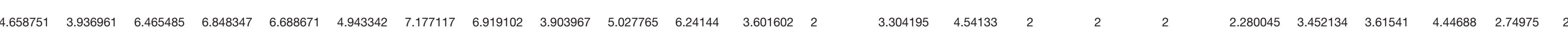
$\begin{array}{llllllllllllllllllllllllll}8.646893 & 10.83833 & 11.3855 & 12.37469 & 11.38546 & 8.808458 & 8.939643 & 11.74084 & 8.530033 & 11.37448 & 10.12337 & 8.253378 & 6.27366 & 4.986856 & 9.104359 & 7.694034 & 5.344538 & 3.140381 & 7.183821 & 8.134469 & 7.937072 & 6.998382 & 6.243838 & 6.24776\end{array}$

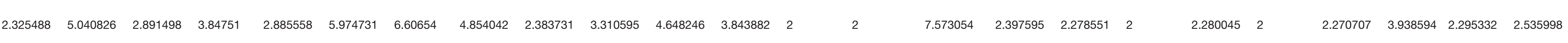

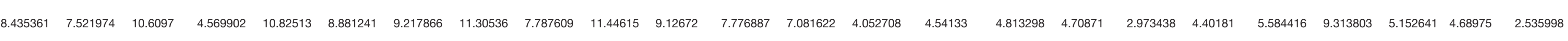

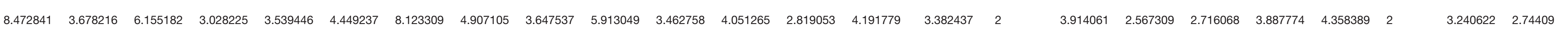

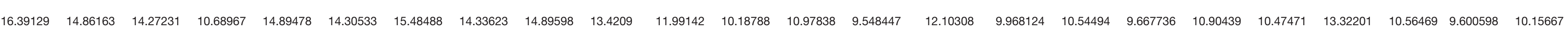

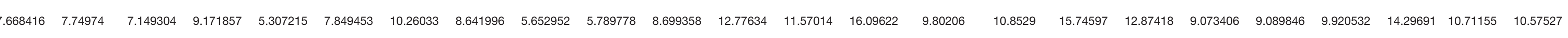
$\begin{array}{llllllllllllllllllllll}7.585881 & 8.666372 & 8.190531 & 6.034866 & 8.578124 & 4.260723 & 2.383731 & 4.627965 & 6.267987 & 5.383231 & 11.67052 & 9.673875 & 10.66956 & 8.816256 & 3.434991 & 12.86695 & 5.700111 & 12.56923 & 4.29912 & 10.85497 & 13.07317 & 6.81875\end{array}$ \begin{tabular}{llllllllllllllllllllllllll}
\hline 874481 & 9.109031 & 9.466512 & 10.20546 & 8.34516 & 7.977548 & 9.756237 & 7.496763 & 4.121623 & 8.382167 & 5.004572 & 9.830375 & 10.82556 & 14.75021 & 8.618071 & 12.98266 & 14.47292 & 11.62108 & 13.21756 & 12.95156 & 9.022359 & 9.1722777 & 11.73312 & 13.29638
\end{tabular} $\begin{array}{llllllllllllllllllllllll}0.559973 & 3.174614 & 4.91758 & 4.505335 & 2.277235 & 3.788143 & 6.216451 & 4.682033 & 2.686545 & 4.073003 & 4.648246 & 7.676101 & 7.5264 & 9.716256 & 7.11889 & 7.379056 & 10.10827 & 9.50089 & 7.329289 & 8.509151 & 11.25627 & 9.30974 & 8.417957 & 6.673669\end{array}$

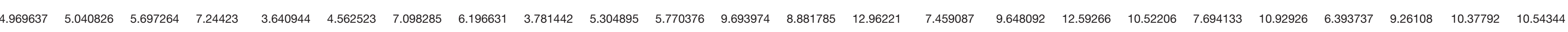

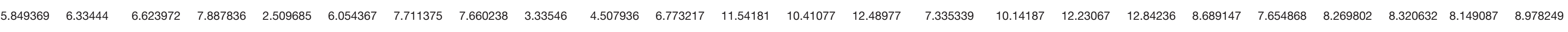

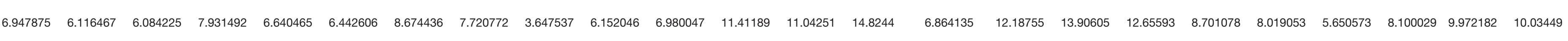

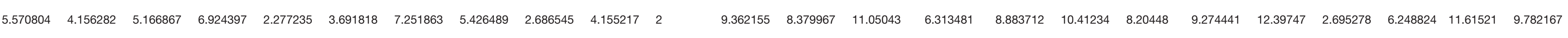

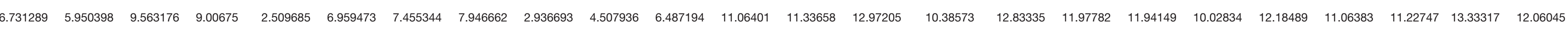
$\begin{array}{lllllllllllllllllllllllll}5.103105 & 5.795724 & 5.90368 & 7.44692 & 4.062829 & 8.229917 & 7.799444 & 7.006799 & 2.686545 & 4.306798 & 5.770376 & 10.90107 & 9.84081 & 11.80922 & 8.758528 & 9.318815 & 11.95509 & 11.65768 & 8.189474 & 9.764453 & 10.08309 & 8.742102 & 8.289777 & 8.542857\end{array}$

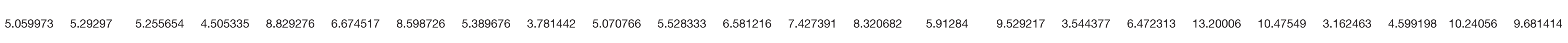

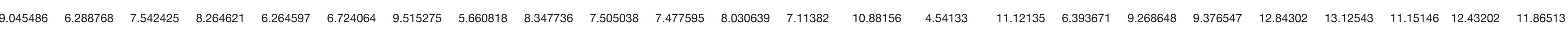

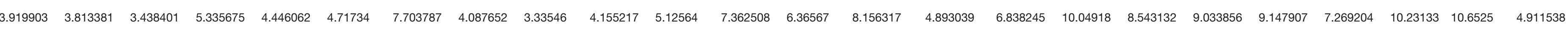

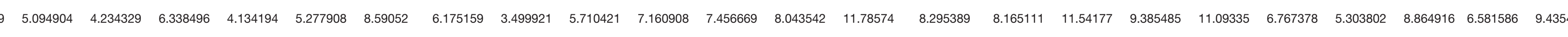

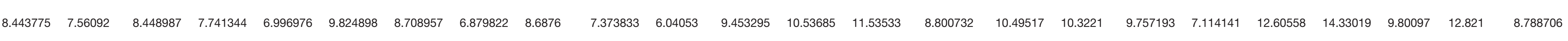


Table S2 Results of CIBERSORT ("A" represents Astrocytoma, "G" represents GBM)

\begin{tabular}{|c|c|c|c|c|c|c|c|c|c|c|c|c|c|c|c|c|c|c|c|c|c|c|c|c|c|}
\hline Sample & $\begin{array}{l}\text { B cells } \\
\text { naive }\end{array}$ & $\begin{array}{l}\text { B cells } \\
\text { memory }\end{array}$ & $\begin{array}{l}\begin{array}{l}\text { Plasma } \\
\text { cells }\end{array} \\
\text { ent }\end{array}$ & $\begin{array}{l}\text { Tcells } \\
\mathrm{CD8}\end{array}$ & $\begin{array}{l}\text { T cells CD4 } \\
\text { naive }\end{array}$ & $\begin{array}{l}\text { T cells CD4 } \\
\text { memory resting }\end{array}$ & $\begin{array}{l}\text { T cells CD4 } \\
\text { memory activated }\end{array}$ & $\begin{array}{l}\text { T cells follicular } \\
\text { helper }\end{array}$ & $\begin{array}{l}\text { T cells regulatory } \\
\text { (Tregs) }\end{array}$ & $\begin{array}{l}\text { T cells gamma } \\
\text { delta }\end{array}$ & $\begin{array}{l}\text { NK cells } \\
\text { resting }\end{array}$ & $\begin{array}{l}\text { NK cells } \\
\text { activated }\end{array}$ & Monocytes & $\begin{array}{l}\text { Macrophages } \\
\text { Mo }\end{array}$ & $\begin{array}{l}\text { Macrophages } \\
\text { M1 }\end{array}$ & $\begin{array}{l}\text { Macrophages } \\
\text { M2 }\end{array}$ & $\begin{array}{l}\text { Dendritic cells } \\
\text { resting }\end{array}$ & $\begin{array}{l}\text { Dendritic cells } \\
\text { activated }\end{array}$ & $\begin{array}{l}\text { Mast cells } \\
\text { resting }\end{array}$ & $\begin{array}{l}\text { Mast cells } \\
\text { activated }\end{array}$ & Eosinophils & Neutrophils & P-value & $\begin{array}{l}\text { Pearson } \\
\text { Correlation }\end{array}$ & RMSE \\
\hline G1 & 0 & 0 & 0.021255 & 0 & 0 & 0.02982 & 0 & 0.05054 & 0.012248 & 0 & 0.048611 & 0 & 0.0926355 & 0.325563 & 0 & 0 & 0 & 0.0006 & 0 & 0.123217 & 0.073848 & 0.221693 & 0.01 & 0.209747 & 1.053869 \\
\hline G2 & 0.007126 & 0 & 0.069559 & 0 & 0 & 0.131187 & 0 & 0.09034 & 0 & 0 & 0.036246 & 0.073768 & 0 & 0.390978 & 0.002289 & 0.190703 & 0 & 0 & 0 & 0.007163 & 0 & 0.0006 & 0.11 & 0.128375 & 1.075117 \\
\hline G3 & 0 & 0 & 0.156878 & 0 & 0 & 0.076898 & 0 & 0.061154 & 0 & 0 & 0.055414 & 0.003927 & 0.03597 & 0.088267 & 0.019239 & 0.36973 & 0 & 0 & 0 & 0.033466 & 0.021532 & 0.077524 & 0.3 & 0.073726 & 1.06218 \\
\hline G4 & 0 & 0 & 0.269493 & 0.099511 & 0.004769 & 0 & 0 & 0.137833 & 0 & 0 & 0 & 0.09237 & 0 & 0 & 0 & 0.332928 & 0 & 0 & 0 & 0.059417 & 0 & 0.003679 & 0.97 & -0.0331 & 1.093059 \\
\hline G5 & 0.078223 & 0 & 0.0119 & 0 & 0 & 0.081814 & 0 & 0.07348 & 0.020759 & 0 & 0.017863 & 0.041676 & 0 & 0.437857 & 0 & 0.157493 & 0 & 0 & 0.047238 & 0 & 0 & 0.031697 & 0.91 & -0.013 & 1.151704 \\
\hline G6 & 0 & 0.009936 & 0.010334 & 0 & 0 & 0.196722 & 0 & 0.052518 & 0 & 0 & 0.069317 & 0.018052 & 0.0004 & 0.311443 & 0 & 0.227514 & 0 & 0.001555 & 0 & 0.08856 & 0 & 0.013643 & 0.02 & 0.173622 & 1.045728 \\
\hline G7 & 0 & 0 & 0.010534 & 0.010315 & 0.033499 & 0.012459 & 0 & 0.006129 & 0 & 0 & 0.094716 & 0 & 0.017828 & 0.687736 & 0 & 0 & 0 & 0 & 0 & 0.126784 & 0 & 0 & 0 & 0.55647 & 0.852898 \\
\hline G8 & 0 & 0.009374 & 0.032023 & 0 & 0 & 0.127675 & 0 & 0.127697 & 0 & 0 & 0.081857 & 0.04766 & 0.033408 & 0.206309 & 0 & 0.221377 & 0 & 0 & 0.042685 & 0 & 0.010044 & 0.059891 & 0.33 & 0.066887 & 1.072258 \\
\hline G9 & 0 & 0 & 0.017113 & 0 & 0 & 0.093871 & 0 & 0.048008 & 0 & 0 & 0 & 0.099695 & 0.158153 & 0 & 0.054591 & 0.276039 & 0 & 0 & 0 & 0.188644 & 0.015248 & 0.048638 & 0.59 & 0.030044 & 1.108175 \\
\hline G10 & 0 & 0.014283 & 0.006073 & 0 & 0 & 0.219659 & 0 & 0.039851 & 0.032903 & 0 & 0.018197 & 0.027607 & 0.018073 & 0.38912 & 0 & 0.163822 & 0 & 0 & 0 & 0.055848 & 0 & 0.014564 & 0.02 & 0.184971 & 1.047569 \\
\hline G11 & 0 & 0 & 0.041072 & 0.034302 & 0 & 0.091885 & 0 & 0.071732 & 0 & 0 & 0.011533 & 0.007397 & 0.086953 & 0.190306 & 0.059727 & 0.302347 & 0 & 0 & 0 & 0.057049 & 0.016003 & 0.029694 & 0.08 & 0.149518 & 1.042882 \\
\hline G12 & 0.019951 & 0 & 0.115304 & 0 & 0 & 0.093642 & 0 & 0.131757 & 0 & 0 & 0.036918 & 0.047937 & 0.096332 & 0.018556 & 0.010984 & 0.254536 & 0 & 0 & 0 & 0.0943 & 0.064787 & 0.014995 & 0.87 & -0.0054 & 1.078999 \\
\hline A1 & 0.077271 & 0 & 0.0724 & 0 & 0 & 0.067586 & 0 & 0.162985 & 0 & 0 & 0 & 0.078885 & 0.241728 & 0 & 0.06472 & 0.131463 & 0 & 0 & 0 & 0 & 0.042562 & 0.0604 & 0.93 & -0.019 & 1.09556 \\
\hline A2 & 0 & 0 & 0.157287 & 0.039707 & 0 & 0.133231 & 0 & 0.098687 & 0 & 0 & 0 & 0.084671 & 0.234276 & 0 & 0 & 0.146869 & 0 & 0 & 0 & 0.10488 & 0 & 0.0004 & 1 & -0.0514 & 1.10294 \\
\hline A3 & 0.097393 & 0 & 0.193297 & 0 & 0 & 0.029905 & 0 & 0.044646 & 0 & 0 & 0 & 0.046772 & 0.108984 & 0.033412 & 0.0031113 & 0.296911 & 0 & 0 & 0 & 0.10768 & 0.02437 & 0.013517 & 0.42 & 0.053568 & 1.060346 \\
\hline A4 & 0.076703 & 0 & 0.225093 & 0 & 0.1588 & 0 & 0 & 0 & 0 & 0 & 0 & 0.049222 & 0.159661 & 0 & 0.004364 & 0.230114 & 0 & 0 & 0 & 0.011737 & 0.056757 & 0.02755 & 1 & -0.0583 & 1.089811 \\
\hline A5 & 0.138777 & 0 & 0.07886 & 0 & 0.161954 & 0.011592 & 0 & 0 & 0 & 0 & 0.060017 & 0.018787 & 0.066033 & 0.01976 & 0 & 0.262631 & 0 & 0 & 0 & 0.125723 & 0.055868 & 0 & 0.98 & -0.0389 & 1.094664 \\
\hline A6 & 0.025796 & 0 & 0.074325 & 0 & 0 & 0.049477 & 0 & 0.056707 & 0 & 0 & 0 & 0.046538 & 0.149874 & 0 & 0 & 0.202911 & 0 & 0 & 0 & 0.328984 & 0.043539 & 0.021848 & 0.11 & 0.135149 & 1.07619 \\
\hline A7 & 0 & 0.023976 & 0.191275 & 0 & 0.034441 & 0.039606 & 0 & 0 & 0 & 0 & 0.002927 & 0.009662 & 0.074021 & 0 & 0 & 0.326844 & 0 & 0 & 0 & 0.234234 & 0.028527 & 0.034488 & 0.82 & 0.002787 & 1.107107 \\
\hline A8 & 0 & 0 & 0.177623 & 0 & 0.041626 & 0 & 0 & 0.061427 & 0 & 0 & 0 & 0.033461 & 0.090843 & 0 & 0 & 0.211869 & 0 & 0 & 0 & 0.331766 & 0.031828 & 0.019557 & 0.43 & 0.052196 & 1.109589 \\
\hline A9 & 0.03469 & 0 & 0.119016 & 0.004411 & 0 & 0.047342 & 0 & 0.022879 & 0.015186 & 0 & 0 & 0.016159 & 0 & 0.132151 & 0.014659 & 0.470202 & 0 & 0 & 0 & 0.073811 & 0 & 0.049494 & 0.14 & 0.115237 & 1.068932 \\
\hline A10 & 0.00713 & 0 & 0.036162 & 0 & 0 & 0.143523 & 0 & 0.024153 & 0 & 0 & 0 & 0.073642 & 0.127215 & 0 & 0.035602 & 0.230768 & 0 & 0.005194 & 0 & 0.259674 & 0.036072 & 0.020863 & 0.29 & 0.080298 & 1.087846 \\
\hline A11 & 0 & 0 & 0.095038 & 0 & 0 & 0.061789 & 0 & 0.039887 & 0 & 0.005814 & 0 & 0.022868 & 0.257673 & 0 & 0 & 0.294874 & 0 & 0 & 0 & 0.130741 & 0.088312 & 0.003004 & 0.08 & 0.144129 & 1.041817 \\
\hline A12 & 0 & 0 & 0.365861 & 0 & 0.033194 & 0.005359 & 0 & 0 & 0 & 0 & 0 & 0.024594 & 0.043111 & 0 & 0 & 0.155775 & 0 & 0 & 0 & 0.276375 & 0.093791 & 0.001936 & 0.87 & -0.0059 & 1.113863 \\
\hline
\end{tabular}

